\title{
Unidades de vegetación de la Argentina
}

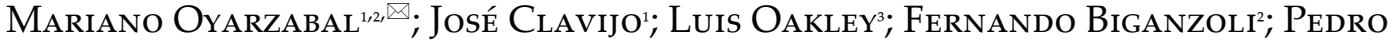 \\ Tognetti $^{122}$; Ignacio Barberis ${ }^{3,4}$; Hernán M. Maturo ${ }^{3}$; Roxana Aragón ${ }^{5}$; Paula I. \\ Campanello ${ }^{6,7} ;$ DariéN Prado $^{3,4}$; Martín Oesterheld ${ }^{1}$ \& Rolando J. C. LeóN ${ }^{1}$ \\ ${ }^{1}$ IFEVA, Facultad de Agronomía, Universidad de Buenos Aires, CONICET. Buenos Aires, Argentina. ${ }^{2}$ Departamento de \\ Métodos Cuantitativos y Sistemas de Información, Facultad de Agronomía, Universidad de Buenos Aires. ${ }^{3}$ Facultad de \\ Ciencias Agrarias, Universidad Nacional de Rosario. Zavalla, Santa Fe, Argentina. ${ }^{4}$ IICAR, Facultad de Ciencias Agrarias, \\ Universidad Nacional de Rosario, CONICET. Zavalla, Santa Fe, Argentina. ${ }^{5}$ Instituto de Ecología Regional, Universidad \\ Nacional de Tucumán, CONICET. Yerba Buena, Tucumán, Argentina. ${ }^{6}$ Instituto de Biología Subtropical, Facultad de \\ Ciencias Forestales, Universidad Nacional de Misiones, CONICET. Puerto Iguazú, Misiones, Argentina. ${ }^{7}$ Centro de Estudios \\ Ambientales Integrados, Facultad de Ingeniería, Universidad Nacional de la Patagonia San Juan Bosco, Esquel, Chubut.
}

\begin{abstract}
Resumen. Existen numerosos mapas de la vegetación espontánea de la Argentina. Sin embargo, no contamos aún con uno de todo el país con una resolución que permita distinguir unidades de vegetación dentro de las provincias fitogeográficas descriptas por Cabrera (1976). Analizamos las descripciones de vegetación publicadas en las últimas décadas, con especial atención sobre aquellas que produjeron mapas fisonómico-florísticos. Como resultado de ese análisis, presentamos aquí un mapa fisonómico-florístico de la vegetación espontánea de la Argentina que muestra la heterogeneidad dentro de provincias fitogeográficas. El mapa tiene 50 unidades de vegetación como subdivisiones de las provincias fitogeográficas y el ecotono descritos con anterioridad, acompañadas de una breve descripción de la fisonomía y composición florística. Proponemos una nomenclatura de las unidades de vegetación según el tipo de vegetación espontánea dominante y especies características, y presentamos material cartográfico electrónico.
\end{abstract}

[Palabras clave: fitogeografía, mapa fisonómico-florístico, vegetación espontánea]

\begin{abstract}
Aвstract. Vegetation units of Argentina. There are numerous maps of the spontaneous vegetation of Argentina. However, a country-level map with enough detail to discriminate vegetation units within the phytogeographic provinces described by Cabrera (1976) is lacking. We analyzed vegetation descriptions published in recent decades, with special attention to those that produced physiognomic-floristic maps. As a result of this analysis, here we present a physiognomic-floristic map of spontaneous vegetation of Argentina that shows the heterogeneity within phytogeographic provinces. The map has 50 vegetation units as subdivisions of the phytogeographic ecotone and provinces early described, and a brief physiognomic-floristic description of each ecotone, province and vegetation unit. We propose a nomenclature of each vegetation unit based on dominant type of spontaneous vegetation and characteristic species and present digital cartographic material.
\end{abstract}

[Keywords: phytogeography, physiognomic-floristic map, spontaneous vegetation]

\section{INTRODUCCIÓN}

Una considerable cantidad de trabajos describieron la vegetación de la Argentina o de algunas de sus regiones. Las descripciones fitogeográficas a nivel país de hace más de cuatro décadas siguen vigentes (Cabrera and Willink 1973; Cabrera 1976; Ribichich 2002). Las descripciones fisonómico-florísticas sobre la base de recorridas o interpretación de fotografías aéreas e imágenes satelitales permitieron elaborar mapas de vegetación del Chaco, del Espinal, de la Mesopotamia, del Monte, de la Pampa y de la Patagonia (Morello 1958; Morello and Adámoli 1968; Anderson et al. 1970; van der Sluijs 1971; Roig 1972; Lewis and Collantes 1973; Anderson et al. 1978; Luti et al. 1979; Cano et al. 1980; Lewis 1981; Soriano et al. 1991; Carnevali 1994; Roig et al. 1996; León et al. 1998; Roig et al. 2009). Editora asociada: Ana Cingolani

\ oyarzaba@agro.uba.ar
Con mayor detalle, algunas áreas fueron evaluadas con una perspectiva fitosociológica, con tablas florísticas completas e identificación de comunidades (e.g., Bertiller et al. 1981a; Golluscio et al. 1982; León and Anderson 1983; Boelcke et al. 1985; Batista et al. 1988; Burkart et al. 1990; Lewis et al. 1990; Martínez Carretero 1995; Fontana 1996; Cingolani et al. 2000; Perelman et al. 2001). Muchas de estas descripciones fisonómico-florísticas resultaron en mapas de vegetación de un distrito político o de una región ecológica.

En las últimas décadas se delimitaron unidades no sólo considerando la vegetación, sino también aspectos sociales como el uso, el deterioro y la conservación (Burkart et al. 1999; Brown and Pacheco 2006). En particular, una iniciativa con escala cartográfica de entre 1:1.000.000 y 1:3.000.000, o más pequeña, fue

Recibido: 9 de julio de 2016

Aceptado: 24 de septiembre de 2017 
publicada recientemente como libro (Morello et al. 2012). El trabajo incluye un mapa que cubre todo el país, cuya área fue dividida en 115 complejos ecosistémicos, agrupados en 15 ecorregiones (sensu Burkart et al. 1999). Según los autores, "[...] No se trata de una mirada exclusivamente fitosociológica, ni fitogeográfica, ni del medio físico, ni de ingeniería ambiental, sino que integra información biofísica y social que modela y regula la estructura y el funcionamiento del paisaje, sus elementos y el tipo de actividades humanas a tres niveles de análisis" (Morello et al. 2012). Como puede entreverse, existe abundante información, pero falta aún una descripción y un mapa integrados de la vegetación espontánea del país que, además, esté disponible en formato digital.

En síntesis, los mapas fisonómico-florísticos disponibles en la actualidad abarcan dos extremos. Algunos cubren todo el país y distinguen provincias fitogeográficas, mientras que otros cubren una región o un distrito político y distinguen comunidades o complejos de comunidades. Falta uno que, manteniendo la escala cartográfica de las descripciones fitogeográficas a nivel país, distinga unidades dentro de las provincias fitogeográficas y esté disponible en formato digital. Nuestro objetivo fue describir y mapear unidades de vegetación fisonómico-florísticas dentro de las grandes unidades fitogeográficas del territorio continental de la Argentina. A diferencia de anteriores, nuestro trabajo describe y mapea exclusivamente rasgos fisonómicoflorísticos de la vegetación espontánea con una resolución intermedia entre comunidad y provincia fitogeográfica, algo aún inédito. Morello et al. (2012) consideraron no sólo la vegetación, sino también otras variables biofísicas y aspectos sociales, por lo que es esperable que los complejos allí descriptos muestren heterogeneidad dentro de unidades mapeadas exclusivamente desde el punto de vista de la vegetación.

Nuestro trabajo se enfoca en la vegetación espontánea. En una parte del país, el tipo de cobertura dominante sigue siendo la vegetación espontánea, poco o muy modificada principalmente por la introducción de ganado doméstico desde fines del siglo XVI. En contraste, en muchas otras zonas la vegetación espontánea fue reemplazada por otra con fines productivos, pero contamos con mapas que extrapolaron la distribución de la vegetación espontánea a toda la región de estudio. Resulta relevante describir la heterogeneidad de la vegetación espontánea, la actual o la que fue reemplazada, porque ayuda a definir desde el punto de vista ecológico y agroecológico la geografía de una región o un país. Esto permite enfrentar de forma más objetiva los problemas asociados al uso de los recursos naturales como, por ejemplo, la invasión de especies exóticas en general o la lignificación de pastizales en particular. Los mapas de este tipo también ayudan a seleccionar modelos de distribución de referencia en iniciativas de restauración, cada vez más numerosas y necesarias en el país y en el mundo (e.g., ver Renison et al. 2013).

\section{MATERIALES y MÉTODOS}

Elaboramos el mapa a partir de relevamientos de vegetación publicados en las últimas décadas (Apéndice 1). Utilizamos especialmente aquellos que, con un criterio fisonómico-florístico, produjeron mapas y lograron una síntesis con un grano o resolución espacial que mostró la heterogeneidad dentro de grandes regiones, pero con una extensión reducida, ya que ninguno cubrió todo el país. Cuando una misma zona fue mapeada por distintos autores, priorizamos aquel mapa cuya resolución fuera más consistente con nuestros objetivos. Para cada provincia fitogeográfica identificada por Cabrera (1976), revisamos los mapas y descripciones disponibles y cartografiamos su heterogeneidad interna. En algunos casos, las unidades cartográficas de nuestro mapa coincidieron con unidades de los trabajos de base; en otros, resultaron de una síntesis ad-hoc. Es decir, delimitamos cada unidad de vegetación a partir de resolver discontinuidades e inconsistencias entre los relevamientos disponibles. Las discontinuidades ocurrieron cuando trabajos de áreas contiguas identificaron de manera diferente a unidades similares. Por ejemplo, la "Estepa arbustiva" descripta en el noreste patagónico hasta el Río Colorado por León et al. (1998), ¿está presente también al norte de ese río, en el sur de la provincia de La Pampa, donde fue llamada "Pastizal de gramíneas bajas con arbustos aislados" por Cano et al. (1980)? ¿O se trata de la continuación hacia el sur de otra unidad, imbricada con la anterior, denominada "Bosque muy abierto, arbustal"? (Cano et al. 1980). Las inconsistencias aparecieron cuando una misma zona fue descripta de distinta manera por más de un trabajo. Por ejemplo, la vegetación espontánea del sudeste de la provincia de San Luis es referida como un "Área medanosa con 
pastizales e isletas de chañar" (Anderson et al. 1970; Soriano et al. 1991) y como un área transicional que se denominó "Mezcla de elementos del Monte y Espinal" (Morello 1958).

No elaboramos nuevos mapas, sino que digitalizamos y georreferenciamos los existentes $y$, cuando fue necesario por discontinuidades y/o inconsistencias que no se pudieron resolver con los documentos, utilizamos nuestra observación en el campo o en Google Earth. Toda esta labor parte del supuesto de que los trabajos originales son los más autorizados a determinar límites entre unidades. Entonces, la mayor parte de lo que se ve en nuestro mapa es el resultado de los mapas que hicieron otros autores (Apéndice 1).

La escala cartográfica del mapa que elaboramos es 1:14.000.000 (Apéndice 2), que reproducido en una página del manuscrito resultó 1:22.000.000 (Figura 1). Naturalmente, la versión digital tiene una escala cartográfica variable (Apéndice 3). Luego del proceso de mapeo descripto más arriba, algunas unidades quedaron comprendidas por un único polígono y otras por varios, como si fueran "islas". Para el caso de estas últimas, aquellos polígonos que resultaron muy pequeños y casi imperceptibles a simple vista los incorporamos a las unidades que los contenían. La superficie de estos polígonos resultó ser menor a 18.000 ha y, por lo tanto, representa la resolución más detallada del mapa, es decir, la mínima unidad independiente que identificamos y digitalizamos. Como la resolución de los mapas de base no es igual, nuestro mapa tiene una resolución heterogénea según la zona o región que se observe. Cartografiamos dos salares de gran extensión en el centro norte del país con un atlas de suelos (INTA 1990). En áreas cubiertas actualmente por vegetación cultivada usamos los mapas que delimitan la vegetación espontánea que fue reemplazada (ver, por ejemplo, León 1979; Soriano et al. 1991; Burkart et al. 2005, 2011). Las formas en que cada trabajo logró este objetivo variaron, pero en esencia se basaron primero en excluir sitios de muestreo con signos claros de modificación antrópica. Luego, se extrapolaron los censos de vegetación espontánea a toda la región de estudio a través de identificar ambientes análogos a los censados, sobre la base de fotointerpretación, relieve, topografía y suelos.

Encuadramos las unidades mapeadas en el esquema fitogeográfico cartografiado de Cabrera (1976), con dos cambios. Por un lado, incorporamos un ecotono documentado (Ecotono Monte-Patagonia) (León et al. 1998; Cingolani et al. 2000). Por otro lado, establecimos límites fitogeográficos ligeramente diferentes a los originales (Cabrera 1976; León et al. 1998). Esto surgió al asignar cada unidad de vegetación a una provincia o ecotono, de modo que la agregación de unidades de vegetación dio origen a dicha provincia o ecotono fitogeográficos. De esta manera hicimos prevalecer la mayor resolución espacial que, respecto al mapa fitogeográfico para todo el país (Cabrera 1976), exhiben los mapas de unidades de vegetación para una región. Agrupamos al ecotono y las provincias fitogeográficas en Dominios, y éstos, a su vez, en Regiones (Cabrera 1976) (el esquema fitogeográfico de Cabrera incluyó también a los Distritos, aunque sin cartografiar).

La descripción que hicimos de cada ecotono y provincia fitogeográfica, y de cada unidad de vegetación, fue fisonómico-florística. Sobre la base de la literatura, describimos el tipo fisonómico de vegetación y las dominantes florísticas. Cuando fue posible, relacionamos las unidades de vegetación con la geomorfología. Para cada unidad, describimos de forma breve las comunidades consideradas zonales y otras regionalmente menos importantes. Las comunidades se identificaron con un número compuesto por el de la unidad a la que pertenecen y por el que identifica a la comunidad. Por ejemplo, la comunidad (18.2) corresponde a la segunda de las descriptas en la unidad 18. Si bien el ecotono y las provincias fitogeográficas están delimitadas sobre la base de endemismos, omitimos una descripción exhaustiva de ellos porque ya está documentada en trabajos más específicos (e.g., Cabrera 1976; Roig et al. 2009; Morrone 2014). La descripción fisonómicoflorística que presentamos es sintética, por lo que puede encontrarse más detalle en los trabajos locales o regionales. Citamos la caracterización fitosociológica disponible de las comunidades más importantes. A diferencia del mapa de Cabrera (1976), las divisiones dentro de las grandes regiones fitogeográficas fueron llamadas "Unidades de Vegetación" (como en León et al. 1988) en lugar de "Distritos" para distinguir que el criterio no fue sólo la afinidad florística (Cabrera 1976), sino también la fisonomía característica (este trabajo). Dada la similitud de escala cartográfica y resolución con otros trabajos, en particular Cabrera (1976) por la escala cartográfica y Morello et al. (2012) por 
la resolución, destacamos su coincidencia cartográfica con trabajos anteriores (Apéndice $1)$.

Los nombres de las unidades de vegetación los asignamos según un criterio fisonómicoflorístico. Las primeras palabras definieron el/los tipos/s fisonómico/s de vegetación dominante/s o característico/s. En algunos casos, esta nomenclatura fisonómica fue seguida por la/s especie/s o género/s dominantes o característicos, o por las formas de vida. Por ejemplo, la selva presente en la provincia de Misiones fue denominada Selva pluvial semicaducifolia, y el bosque que ocupa parte de la provincia de La Pampa fue llamado Bosque de esclerófitas con Prosopis caldenia. Excepcionalmente, algunos nombres incluyen rasgos geomorfológicos como, por ejemplo, Selva pluvial semicaducifolia pedemontana. A otros se les agregó la fisonomía de comunidades secundarias desde el punto de vista de su dominancia. Entre paréntesis agregamos el/los nombres populares o más conocidos. Los nombres de los géneros y especies corresponden a los aceptados para la flora del Cono Sur (www.darwin.edu.ar/ Proyectos/FloraArgentina/Especies.asp), aunque, para facilitar la lectura, en el texto principal omitimos las siglas de las autoridades y las detallamos aparte (Apéndice 4). Los nombres del ecotono y de las provincias fitogeográficas son los originales (Cabrera 1976; León et al. 1998).

\section{Resultados}

Delimitamos 50 unidades de vegetación, agrupadas en un ecotono y once provincias fitogeográficas, agrupados a su vez en cuatro dominios y dos regiones (Cabrera 1976) (Figura 1). A continuación, describimos brevemente, desde el punto de vista fisonómico-florístico, el ecotono y las provincias fitogeográficas, y las unidades de vegetación.

\section{Provincia Fitogeográfica de las Yungas}

Las Yungas constituyen, junto a la Selva Paranaense, las dos provincias con selvas subtropicales de la Argentina. Las Yungas en la Argentina ocupan las laderas orientales de las Sierras Subandinas y Pampeanas, en un rango altitudinal entre 400 y $3000 \mathrm{~m}$ s.n.m. (Hueck 1972; Brown et al. 2001). Esta variación en altura se relaciona también con una variación en la precipitación media anual (de 600 a $3000 \mathrm{~mm}$ ), que, en gran medida, determina una distribución de vegetación en pisos altitudinales. Las especies más resistentes a la sequía se ubican en las partes más bajas (Selva pluvial semicaducifolia pedemontana), mientras que las tolerantes a mayor humedad y a heladas, en los pisos más elevados (Selva y Bosque montanos) (Brown et al. 2001). Este gradiente ambiental amplio permite la coexistencia de especies de orígenes biogeográficos distintos. El tipo de vegetación dominante es la selva de neblina con árboles de follaje perenne o semicaducifolio, con dos o tres estratos y abundantes lianas y epífitas. El estrato superior tiene una altura mayor a 25 $\mathrm{m}$, el medio entre 5 y $12 \mathrm{~m}$, y el inferior, con arbustos del sotobosque, una altura de entre 3 y $5 \mathrm{~m}$. Aunque las Yungas ocupan $1 \%$ del territorio argentino, poseen, junto con la selva Paranaense (de similar superficie), $~ 50 \%$ de la biodiversidad del país (Brown et al. 2001).

Unidad 1. Selva y Bosque montanos (Selva Montana y Bosque de Aliso y Pino del cerro). Representa el piso intermedio (entre 700 y 1500 m s.n.m.) y superior (1500 a 3000 m s.n.m.) de las Yungas. Incluye cuatro comunidades predominantes. La selva montana tiene dos, (1.1) Selva basal de Tipuana tipu y Ocotea porphyria, y (1.2) Selva de Mirtáceas de Eugenia uniflora, Blepharocalyx salicifolius y Myrcianthes pungens (Grau and Brown 1995; Morales et al. 1995; Brown et al. 2001). El bosque montano (1.3) está dominado por especies de origen Gondwanico como Podocarpus parlatorei y Fuchsia boliviana, y de origen Holártico como Alnus acuminata, Juglans australis e Ilex argentina. En el límite superior de este bosque se desarrolla un pastizal de neblina (1.4), que en el gradiente altitudinal aparece primero disperso y luego dominante, con Festuca hieronymi, Deyeuxia polygama y Elionurus muticus, y arbustos de los géneros Baccharis y Stevia (Aragón et al. 2005). Además, suelen crecer individuos de Polylepis australis, aislados o formando pequeños bosques.

Unidad 2. Selva pluvial semicaducifolia pedemontana(SelvadeTransición). Representa el piso inferior de las Yungas, entre 400 y $700 \mathrm{~m}$ s.n.m., con una precipitación media anual de entre 600 y $1000 \mathrm{~mm}$. Ocupa las áreas ecotonales con el bosque chaqueño (Cabrera 1976). Las especies caducifolias son más abundantes que en los otros pisos altitudinales. Algunos trabajos consideran que esta unidad tiene más elementos comunes con el Chaco que con las Yungas, y la denominan "Selva de transición" (Cabrera 1976). Sin embargo, esta unidad 
tiene fisonomía y composición florística claramente distinguibles. Se reconocen dos comunidades limitadas por las serranías próximas a la ciudad de Metán (Morales et al. 1995; Prado 1995; Brown et al. 2001). (2.1) Selva de Calycophyllum multiflorum y Phyllostylon rhamnoides, al norte, y (2.2) Selva de Tipuana tipu y Enterolobium contortisiliquum, al sur. Además de las ya mencionadas, las especies dominantes son Handroanthus impetiginosus, Cordia americana y Astronium urundeuva en el norte, y Anadenanthera colubrina, tanto en el norte como en el sur (Cabrera 1976). En gran parte, la vegetación natural de esta unidad fue reemplazada por agricultura y ganadería, o modificada por tala selectiva de especies como Juglans australis y Cedrela angustifolia, y en la actualidad tiene los menores esfuerzos de conservación (Brown et al. 2001).

\section{Provincia Fitogeográfica Paranaense}

El tipo de vegetación predominante es la selva. Hay también bosque dealbardón, bosque de Bambúseas, bosque en galería, sabana, pastizal alto y matorral de leguminosas. Es probablemente la provincia fitogeográfica del país con mayor riqueza específica vegetal. Comparte con la provincia de las Yungas, en particular con la Selva pluvial semicaducifolia pedemontana (unidad 2), y con otros bosques secos estacionales neotropicales, un alto porcentaje de géneros y especies comunes o fuertemente emparentadas (Cabrera 1976; Prado 2000; Pennington et al. 2009; Morello et al. 2012).

Unidad 3. Selva pluvial semicaducifolia (Selva Misionera; Selva Paranaense). Tiene tres estratos arbóreos, con lianas, epífitas y hemiepífitas, y un sotobosque de helechos y fanerófitas herbáceas y arbustivas, incluidas Bambúseas. Comprende más de 3000 especies vasculares (Giraudo et al. 2003). El relieve onduladoylosnumerosos ríos y arroyos afectan la distribución de especies por sus efectos en las condiciones ambientales (Matteucci et al. 2004). La unidad comprende dos de las ocho subregiones del Bosque Atlántico (Cardoso da Silva and Casteleti 2003). a) Bosque Interior, que ocupa la mayor parte de la unidad, donde se distinguen: (3.1) Selva con Nectandra spp., Ocotea spp. y Balfourodendron riedelianum; (3.2) Selva con Aspidosperma polyneuron y Euterpe edulis; y (3.3) Selva con Astronium balansae (Martínez-Crovetto 1963; Cabrera 1976). La otra subregión es b) Bosque mixto con Araucaria (3.4), en manchones en el nordeste de la unidad (ver sin embargo Ríos et al. 2010), donde además de las especies listadas en la comunidad 3.1 aparecen Araucaria angustifolia e Ilex paraguariensis.

Unidad 4. Bosque ribereño subtropical (Valle del Paraná). Incluye cuatro comunidades, cuya distribución espacial depende del régimen de inundación del eje fluvial Paraguay-Paraná (Neiff 1997; Casco et al. 2005). (4.1) Bosque monoespecífico de higrófitas, de Tessaria integrifolia o de Salix humboldtiana. Ocupa albardones arenosos de reciente formación. (4.2) Bosque pluriespecífico de higrófitas, con Albizia inundata, Inga uraguensis, Croton urucurana, etc. Ocupa albardones antiguos con suelos más desarrollados. Más hacia el sur se empobrece florísticamente y dominan Nectandra angustifolia, Myrsine laetevirens, etc. (Franceschi et al. 1985). (4.3) Pastizal alto de gramíneas higrófitas como Coleataenia prionitis, Hymenachne grumosa, Panicum elephantipes y Echinochloa polystachya. Ocupa planicies que permanecen gran parte del año inundadas ("bañados"). (4.4) Formaciones de herbáceas acuáticas ("madrejones") con Eichhornia spp., Pistia stratiotes, etc. Ocupan cuerpos de agua permanentes, entre los albardones y los bañados.

Unidad 5. Bosque y humedal deltaicos (Delta del Paraná). Incluye cuatro comunidades, cuya distribución espacial depende de la acción combinada del régimen de inundación de los ríos Paraná y Uruguay, y de las crecidas y mareas estuariales del Río de la Plata (Burkart 1957; Malvárez 1997). (5.1) Bosque y Arbustal monoespecífico de higrófitas, de Baccharis salicifolia, de Tessaria integrifolia o de Salix humboldtiana. Ocupa albardones arenosos recientes. (5.2) Bosque pluriespecífico de higrófitas con Nectandra angustifolia, Myrsine laetevirens, etc. y abundantes lianas y epífitas. Ocupa albardones antiguos con suelos desarrollados. (5.3) Pastizal alto y/o Pradera monoespecífico/a de higrófitas, de Cortaderia selloana, Coleataenia prionitis, Eryngium pandanifolium, Ludwigia peploides, Polygonum spp., Schoenoplectus californicus o Zizaniopsis bonariensis. Ocupa depresiones inundadas gran parte del año. (5.4) Formaciones de herbáceas acuáticas con Eichhornia spp., Cabomba australis, Hydrocleys nymphoides, etc. Ocupan cuerpos de agua permanentes y orillas de cursos. Hay también otros bosques de higrófitas (4.1 y 4.2) (Cabrera 1976).

\section{Provincia Fitogeográfica Prepuneña}

Ocupa las laderas orientales secas y quebradas de las Sierras Subandinas y 
Pampeanas en el noroeste del país, entre los 2000 y 3400 m s.n.m. en la parte norte, y entre los 1000 y 3000 m s.n.m. en el extremo sur (Cabrera 1976). La precipitación es principalmente estival y menor a $200 \mathrm{~mm} /$ año. En general, la presencia de la Prepuna está condicionada no sólo por la altura, sino muy particularmente por la disposición y orientación de las quebradas (Cabrera 1976). La vegetación presenta adaptaciones a la falta de agua, como tejidos que la acumulan (Trichocereus spp.), plantas en forma de cojín (Deuterocohnia brevifolia), hojas pequeñas o afilia (Junellia juniperina), entre otras. La vegetación típica es la estepa arbustiva, a veces con pequeños árboles, y la presencia característica de Cactáceas columnares de gran tamaño del género Trichocereus. Esta provincia podría ser redefinida en un futuro con nuevos estudios florísticos, ya que, aunque tiene una fisonomía distintiva, carece de especies endémicas que la definan en todo su rango de extensión (López 2000; López and Beck 2002; Aagesen et al. 2009, 2012).

Unidad 6. Estepa arbustiva con Trichocereus spp. (Prepuna). La comunidad típica es una estepa arbustiva de dos estratos (6.1). El estrato superior está dominado por la cactácea columnar Trichocereus atacamensis, acompañada de arbustos o árboles bajos como Prosopis ferox, Gochnatia glutinosa, Senna crassiramea, Aphyllocladus spartioides, Cercidium andicola, Zuccagnia punctata, entre otros. El estrato inferior es de Cactáceas rastreras y globosas como Airampoa ayrampo, Tunilla tilcarensis, Parodia maassii, Parodia stuemeri, y numerosas gramíneas como Digitaria californica, Munroa argentina, Jarava leptostachya, Jarava media o Eragrostis andicola (Aagesen et al. 2009). Por encima de los $3000 \mathrm{~m}$ s.n.m. Trichocereus tarijensis reemplaza muchas veces a Trichocereus atacamensis. Hay también una estepa con Bromeliáceas terrestres (6.2), muchas de ellas en cojín, que ocupa las laderas rocosas con pendiente pronunciada, dominada por Deuterocohnia brevifolia, Deuterocohnia lorentziana, Deuterocohnia digitata, Tillandsia virescens, Puya castellanosii y Puya dyckioides, entre otras (Cabrera 1976).

\section{Provincia Fitogeográfica Chaqueña}

Los tipos de vegetación zonal dominantes son el bosque y la sabana tipo parque. El bosque es de xerófitas. En general está dominado por alguna de las especies del género Schinopsis (Ragonese and Castiglioni 1970; Prado 1993a), con una altura de hasta
25 m, junto con Aspidosperma quebracho-blanco, Ceiba chodatii, Ziziphus mistol y leguminosas mimosoideas. El otro tipo de vegetación es la sabana tipo parque, con las mismas xerófitas arbóreas y un estrato herbáceo dominado por gramíneas cespitosas megatérmicas. Las variantes de estos tipos de vegetación zonales, $\mathrm{u}$ otros tipos zonales y azonales de menor extensión y constancia permiten distinguir doce unidades.

Unidad 7. Bosque de xerófitas con Schinopsis marginata (Chaco Serrano). Está conformado por tres comunidades, de las cuales sólo la primera es zonal. (7.1) Bosque abierto de xerófitas con Schinopsis marginata. Ocupa suelos someros de los faldeos y quebradas de las Sierras Pampeanas y Subandinas, entre 500-1300 m s.n.m. (Luti et al. 1979). La composición florística varía con la latitud, la altitud, el suelo y los disturbios (Cabido et al. 1991). En los faldeos septentrionales, las principales acompañantes son Ceiba chodatii, Aspidosperma quebracho-blanco y Ruprechtia apetala; mientras que en los faldeos del sur abundan Lithraea molleoides, Zanthoxylum coco y Trithrinax campestris. (7.2) Matorral serrano con Acacia caven, Eupatorium buniifolium, Heterothalamus alienus, Flourensia campestris, etc. Ocupa laderas y pedemontes con afloramientos rocosos, entre 1300-1700 m s.n.m. (7.3) Bosque de Polylepis australis. A mayor altitud, el bosque de Polylepis ocupa ambientes similares a la comunidad 7.2, y en ocasiones forma mosaicos con la unidad 8 (ver más abajo).

Unidad 8. Pastizal de Stipeas y Festuceas (Pastizales de Altura). Caracterizada por una comunidad zonal y otra higrófitica azonal. (8.1) Pastizal de gramíneas cespitosas mesotérmicas ("Pastizal de altura") (Cabrera 1976). Ocupa los filos de cerros y serranías y constituye el último piso de vegetación de las Sierras Pampeanas y Subandinas, por encima de 17001900 m s.n.m. (Luti et al. 1979; Cingolani et al. 2004; Martínez et al. 2016). Su composición florística fundamental está dada por Poáceas de la tribu Stipeas (Nassella filiculmis, Nassella niduloides, Nassella tenuissima, etc.) o de la tribu Festuceas (Festuca hieronymi, Festuca lilloi, Poa stuckertii, Deyeuxia hieronymi, y otras). (8.2) Como comunidad azonal se encuentra una pradera de higrófitas de altura, en sitios donde se acumula humedad y aparecen hierbas como Lachemilla pinnata, Eleocharis pseudoalbibracteata, Carex gayana. Donde el agua fluye son comunes las poblaciones de Cortaderia selloana (Cabido et al. 2010). 
Unidad 9. Bosque de xerófitas con Aspidosperma quebracho-blanco en transición a estepa (Chaco Árido). La vegetación zonal se compone de especies xerófitas dispuestas en bosques abiertos y estepas arbustivas (Cabido et al. 1994). Consiste de una gradual transición entre las provincias Chaqueña y del Monte (Cabido et al. 1993), a lo largo de extensas llanuras interserranas ("bolsones" o "llanos") (Morello 1958). (9.1) Bosque abierto de xerófitas, de hasta $10 \mathrm{~m}$ de altura, con Aspidosperma quebracho-blanco emergiendo sobre el dosel. Ocupa planicies y zonas intermedanosas, con suelos arenosos y pobres de materia orgánica. Las acompañantes son Cercidium praecox, Ziziphus mistol, Larrea cuneifolia, Larrea divaricata, Capparis atamisquea, Mimozyganthus carinatus, Cereus forbesii y Acacia gilliesii. Las diferencias fundamentales entre esta unidad y la vecina (12.1; ver más abajo) es la ausencia de Schinopsis lorentzii y la mayor frecuencia de especies arbustivas de la provincia fitogeográfica del Monte. (9.2) Estepa arbustiva de xerófitas, de hasta $2.5 \mathrm{~m}$ de altura y cobertura entre 30 y 50\%, con Senna aphylla, Condalia microphylla, Ximenia americana, Cereus aethiops, Tephrocactus articulatus, Bulnesia retama, Zuccagnia punctata, Prosopis torquata y Opuntia sulphurea. Ocupa planicies y médanos fósiles de textura franco-arenosa. A las anteriores se agregan dos comunidades azonales. (9.3) Bosque abierto freatofítico de Prosopis flexuosa, Prosopis chilensis y Geoffroea decorticans, y (9.4) Matorral de halófitas, que ocupa suelos arcillo-limosos asociados a cauces alóctonos ("barriales") (Morello 1958).

Unidad 10. Matorral de halófitas (Salinas Grandes). Complejo de dos comunidades azonales cuya distribución espacial se da en zonaciones bien definidas en la cuenca de las Salinas Grandes, rodeando sectores totalmente cubiertos de sal y desprovistos de vegetación (Ragonese 1951; Sayago 1969). (10.1) Matorral de halófitas suculentas obligadas, como Allenrolfea patagonica, Allenrolfea vaginata, Heterostachys ritteriana, Atriplex cordobensis, Sarcocornia ambigua, Cressa nudicaulis, etc. Ocupa planicies con eflorescencias salinas. (10.2) Matorral de xerófitas con halófitas facultativas como Stetsonia coryne, Lycium spp., Cyclolepis genistoides, Cortesia cuneifolia, Maytenus vitis-idaea, etc. Ocupa suelos mejor drenados, constituyendo cinturones de vegetación que rodean a la comunidad anterior. Se trata de un área de transición con el Bosque de la unidad 9 (ver más arriba). Hay también parches de una comunidad zonal, el Bosque de xerófitas con Aspidosperma quebracho-blanco, Mimozyganthus carinatus, Larrea divaricata, Cercidium praecox, etc. Ocupa sectores elevados dentro de la matriz de llanura, con suelos ricos en yeso (Sayago 1969).

Unidad 11. Pastizal y Matorral de halófitas (Bañados de Mar Chiquita; Espartillares y zampales). Se trata de un conjunto de comunidades salinas azonales, cuya distribución espacial se da en fajas de amplitud variable, paralelas al sistema fluvial de los bañados del río Dulce y laguna Mar Chiquita (Menghi 2006). (11.1) Comunidades de hierbas palustres como Typha latifolia, Schoenoplectus americanus, etc. Ocupan los sitios aledaños a las orillas de los cuerpos de agua. (11.2) Pastizal alto y/o Pradera de gramíneas halófitas facultativas como Spartina spartinae, Spartina densiflora y Distichlis spicata. Ocupa planicies de suelos muy salinos que permanecen inundada parte del año. (11.3) Matorral de halófitas obligadas como Atriplex argentina, Sarcocornia ambigua, Allenrolfea vaginata, Heterostachys ritteriana. Ocupa planicies con eflorescencias salinas y napa freática muy cercana a la superficie. (11.4) Bosque y/o Arbustal de transición a las comunidades 12.1 o 12.5 (ver más abajo), en albardones y terrazas recientes de los bañados y la laguna mencionados, con Celtis ehrenbergiana, Prosopis alba, Baccharis salicifolia, Tessaria dodoneifolia, etc.

Unidad 12. Bosque de xerófitas con Schinopsis lorentzii (Chaco Semiárido). Tiene cuatro comunidades zonales. (12.1) Bosque cerrado de xerófitas, de entre 15 y $25 \mathrm{~m}$ de altura, con Schinopsis lorentzii y Aspidosperma quebracho-blanco. Ocupa suelos limo-arenosos. Acompañan Ceiba chodatii y Ziziphus mistol. Hacia el suroeste es más abierto y aparecen Cercidium praecox y Larrea divaricata. (12.2) Bosque de xerófitas con Bulnesia sarmientoi y Aspidosperma triternatum. Ocupa suelos arcillo-limosos. (12.3) Pastizal de Cenchrus pilcomayensis sobre paleocauces arenosos. (12.4) Bosque de xerófitas de Prosopis spp. Ocupa llanuras aluviales de los ríos Salado y Dulce. También existen cuatro comunidades azonales. (12.5) Bosque y/o Arbustal de higrófitas con Salix humboldtiana, Tessaria dodoneifolia y Baccharis salicifolia en albardones y terrazas recientes de los ríos Bermejo, Dulce y Salado. (12.6) Matorral de xerófitas sobre áreas con modelado fluvial reciente y predominio de suelo desnudo ("peladares"; Morello and Adámoli 1974). (12.7) Bosque secundario de 
Prosopis ruscifolia (Morello et al. 1971) y Acacia aroma. (12.8) Estepa de halófitas.

Unidad 13. Bosque de xerófitas con Schinopsis balansae y Schinopsis lorentzii, y Pastizal (Chaco Subhúmedo). Tiene dos comunidades zonales. (13.1) Bosque de xerófitas cerrado a semiabierto, donde codominan Schinopsis balansae, S. lorentzii y Aspidosperma quebrachoblanco. Ocupa suelos altos, de textura limo-arenosa. Las principales especies acompañantes son el híbrido interespecífico Schinopsis heterophylla, Ceiba chodatii y Ziziphus mistol ("Bosque de tres quebrachos") (Torrella et al. 2011). (13.2) Pastizal dominado por gramíneas cespitosas megatérmicas como Elionurus muticus y Cenchrus pilcomayensis. Ocupa sectores enclavados en el paisaje de la comunidad 13.1 ("abras" o "pampas") (Morello and Adámoli 1974). Este pastizal también asienta sobre paleocauces con suelos arenosos (Adámoli comunicación personal). Las comunidades azonales son (13.3) Bosque y/o Arbustal de higrófitas con Salix humboldtiana, Tessaria dodoneifolia y Baccharis salicifolia en albardones y terrazas recientes del río Bermejo. (13.4) Bosque secundario de Prosopis ruscifolia (Morello et al. 1971).

Unidad 14. Sabana de Copernicia alba y Sorghastrum setosum, y Mosaico de Bosques (Chaco Húmedo con Bosques, Pajonales y Palmares de Caranday). Mosaico complejo de siete comunidades en la porción terminal de los abanicos aluviales de los ríos Bermejo y Pilcomayo (Morello and Adámoli 1967), en albardones, paleoalbardones e interfluvios deprimidos. Incluye tres comunidades zonales. (14.1) Bosque de mesófitas con especies de linaje extra-chaqueño ("Bosque Transicional Austro-Brasileño - BTAB") (Prado 1993b) como Peltophorum dubium, Pisonia zapallo, Phyllostylon rhamnoides, etc. Ocupa albardones antiguos y paleoalbardones, franco-limosos. (14.2) Bosque de xerófitas con Schinopsis balansae, en áreas algo deprimidas e inundables con suelos arcillosos, linderas con los albardones anteriores (14.1). (14.3) Sabana de Elionurus muticus e Imperata brasiliensis, con Erythrina dominguezii, Chloroleucon chacoense y Tabebuia aurea, en paleoalbardones arenosos. Las cuatro comunidades restantes son azonales. (14.4) Bosque ribereño de higrófitas con Albizia inundata, Inga uraguensis, etc. ("Selva en Galería"), en albardones recientes francolimosos. (14.5) Palmar de Copernicia alba, en suelos arcillosos, anegables. (14.6) Pastizal alto de higrófitas con Sorghastrum setosum, en suelos hidromórficos. (14.7) Formaciones de palustres como Cyperus giganteus y Thalia geniculata, en depresiones inundadas.

Unidad 15. Mosaico de Bosque de xerófitas, de mesófitas, Sabana y Selva de albardón (Chaco Húmedo con Bosques y Cañadas). Mosaico complejo de seis comunidades cuya distribución espacial depende del relieve y régimen hídrico. Las dos primeras son zonales. (15.1) Bosque de mesófitas con especies de linaje extra-chaqueño (BTAB) como Cordia americana, Gleditsia amorphoides, Pisonia zapallo, Handroanthus heptaphyllus, en suelos altos, francos. Hacia el norte se enriquece con Holocalyx balansae (Prado et al. 1989). (15.2) Bosque semiabierto de xerófitas dominado por Schinopsis balansae, con Aspidosperma quebrachoblanco, Prosopis nigra, Caesalpinia paraguariensis y Ziziphus mistol, en suelos franco-arcillosos, a veces dispuesto en parches (Morello and Adámoli 1974). Las comunidades restantes son azonales.(15.3) Bosque ribereñopluriespecífico de higrófitas ("Selvas de Ribera"; Morello and Adámoli 1974) con Albizia inundata, Nectandra sp., etc., en albardones de arroyos y riachos. (15.4) Sabana-Palmar de Copernicia alba, en suelos arcillosos, anegables. (15.5) Pastizal alto de higrófitas con Sorghastrum setosum, Paspalum intermedium y Coleataenia prionitis, en suelos hidromórficos. (15.6) Formaciones de herbáceas palustres de Cyperus giganteus y Thalia geniculata, en depresiones inundadas.

Unidad 16. Pastizal de Spartina spartinae (Bajos Submeridionales; Espartillares). Tiene tres comunidades azonales, cuya distribución espacial depende del gradiente topográfico y cuya estructura está influenciada por inundaciones recurrentes y fuego (Lewis et al. 1990). (16.1) Pastizal alto de Spartina spartinae, halófita facultativa ("espartillar") (Lewis 1981). Ocupa suelos arcillo-halomórficos, muy mal drenados. (16.2) Sabana muy abierta con matriz de Elionurus muticus y otras gramíneas megatérmicas como Bothriochloa spp. y Chloris canterae, y pocas especies arbóreas como Geoffroea decorticans y Prosopis nigra. Ocupa suelos más altos, mejor drenados. (16.3) Pradera de halófitas con Distichlis spicata, Sarcocornia ambigua, Sesuvium portulacastrum, etc. Ocupa suelos con eflorescencias salinas y napa freática muy cercana a la superficie. (16.4) Hay también mosaicos de Pastizal alto y Pradera de higrófitas, con Paspalum vaginatum, Schoenoplectus californicus, Typha domingensis, etc., que ocupan depresiones que permanecen inundadas por largos períodos. 
Unidad 17. Sabana de Andropogon lateralis y Paspalum notatum (Pajonales y Palmares de Yatay). Contiene seis comunidades principales, dos de ellas zonales. (17.1) Sabana-Parque con matriz de gramíneas megatérmicas, principalmente Andropogon lateralis y Paspalum notatum, y agrupaciones de Prosopis affinis, Acacia caven, Celtis chichape, entre otras. Ocupa lomadas con suelos arenosos bien drenados. Son comunes las palmeras, Butia yatay al suroeste y Butia paraguayensis al noreste. (17.2) Bosque de xerófitas con Aspidosperma quebracho-blanco, Prosopis nigra, Copernicia alba. Ocupa suelos arcillosos. Las cuatro restantes son comunidades azonales. (17.3) Pastizal de Andropogon lateralis, Paspalum durifolium, Axonopus spp. y Rhynchospora tenuis ("Malezal"). Ocupa planicies con suelos muy hidromórficos y microrrelieve con alternancia de pequeños canales de escorrentía y elevaciones (Carnevali 1994). (17.4) Bosque de higrófitas con Gleditsia amorphoides, Allophylus edulis, Sebastiania spp., etc. Ocupa albardones antiguos. (17.5) Bosque en galería en orillas de cursos de agua, con Inga uraguensis, Albizia inundata, etc. (17.6) Formaciones de herbáceas palustres con Cyperus giganteus, Typha latifolia, etc. Ocupan esteros y bañados.

Unidad 18. Mosaico de comunidades higrófiticas (Esteros del Iberá). Incluye tres comunidades, todas azonales. (18.1) Formaciones de herbáceas acuáticas y palustres. Ocupan cuerpos de agua permanentes, como bañados, esteros y lagunas. Las acuáticas (Pistia stratiotes, Eichhornia spp. - "camalotes", etc.) crecen en espejos de agua y las palustres en la periferia, constituyendo zonaciones repetitivas, como por ejemplo las comunidades de higrófitas con Cyperus giganteus ("pirizales"), con Typha latifolia ("totorales"), con Paspalum durifolium ("pajonales"), entre otras. (18.2) Entramado flotante de acuáticas y palustres que acumula materia orgánica y favorece el crecimiento de algunas leñosas ("embalsados"). (18.3) Palmar y Pastizal. Ocupa lomadas del noroeste. Forma un mosaico de sabana de Copernicia alba y pastizal de Andropogon lateralis, Paspalum durifolium, Axonopus spp. y Rhynchospora tenuis ("malezal"). Se desarrolla sobre suelos con marcado hidromorfismo y microrrelieve con alternancia de pequeños canales de escorrentía y elevaciones.

\section{Provincia Fitogeográfica del Espinal}

La vegetación es una combinación de especies arbóreas o arbustivas. Predominan las leguminosas mimosoideas con características xerofíticas y un estrato herbáceo dominado por gramíneas cespitosas. Los tipos de vegetación dominantes son el bosque, que en algunos casos ocupa una superficie considerable, y la sabana, desde muy abierta hasta tipo parque. La vegetación típica zonal está representada por el bosque esclerofítico, abierto, dominado por especies del género Prosopis, con una altura de hasta $10 \mathrm{~m}$, y por la sabana, con una matriz de gramíneas megatérmicas o mesotérmicas dependiendo de la latitud (Lewis and Collantes 1973; Cabrera 1976). Las variantes de los tipos de vegetación zonales, más otras menos importantes por la superficie que cubren y su constancia regional, que representan formaciones azonales, permiten distinguir las cuatro unidades que se detallan a continuación.

Unidad 19. Bosque de esclerófitas con Prosopis affinis (Nandubayzal y Selva de Montiel). Tiene tres comunidades; las dos primeras son zonales. (19.1) Bosque xerofítico abierto de Prosopis affinis. Ocupa llanuras planas y lomas bajas. Las especies acompañantes son Aspidosperma quebrachoblanco, Celtis ehrenbergiana y Prosopis nigra, y puede ser abundante la palmera Trithrinax campestris. (19.2) Sabana abierta con gramíneas megatérmicas o mesotérmicas e individuos de Prosopis affinis o Acacia caven. La sabana con gramíneas megatérmicas (Andropogon lateralis) en colinas del norte, y la de gramíneas mesotérmicas (Nassella spp.) sobre lomas altas al sur ("cuchillas"). (19.3) Palmar de Butia yatay. Desarrolla sobre lomadas arenosas y terrazas del río Uruguay (Martínez-Crovetto and Piccinini 1950; Batista et al. 2014). Hay también bosque en galería con especies paranaenses en ríos y arroyos (León and Movia 1981).

Unidad 20. Bosque de esclerófitas con Prosopis nigra y Acacia caven (Espinillar). La vegetación zonal está compuesta por un bosque xerofítico y una sabana, abiertos. (20.1) Bosque xerofítico abierto dominado por Prosopis nigra y Acacia caven. Ocupa llanuras planas a levemente onduladas. Las especies dominantes son acompañadas por Geoffroea decorticans, que en ocasiones se comporta como invasora. (20.2) Sabana muy abierta con una matriz de gramíneas megatérmicas (por ejemplo, Leptochloa chloridiformis), con ejemplares de las especies arbóreas de la comunidad 20.1. Típica de lomadas con suelos profundos. Se encuentran, además, las siguientes comunidades azonales. (20.3) Pastizal alto de gramíneas fasciculadas (Coleataenia prionitis, 
Spartina spartinae), en posiciones topográficas bajas, sujetas a anegamientos periódicos. (20.4) Comunidades de halófitas sobre suelos salobres.

Unidad 21. Bosque de esclerófitas con Prosopis nigra y Prosopis alba (Algarrobal). Tiene tres comunidades importantes ubicadas en distintas posiciones topográficas. (21.1) Bosque de Prosopis spp. que desarrolla en lomadas. Al este hay bosque abierto de Prosopis nigra y Acacia caven. En el centro existen formaciones boscosas donde los Prosopis dominantes son acompañados por Celtis ehrenbergiana y puede ser abundante la palmera Trithrinax campestris (Lewis et al. 2009). Al noroeste se da un bosque de Prosopis nigra y Prosopis alba, con Aspidosperma quebracho-blanco. Al sudoeste hay un bosque de Prosopis caldenia. (21.2) Sabana de leñosas. Se ubica en áreas periódicamente anegables y está dominada por Geoffroea decorticans, Acacia caven y Parkinsonia aculeata. (21.3) Pradera de higrófitas y halófitas. Desarrolla en bajos y cañadas.

Unidad 22. Bosque de esclerófitas con Prosopis caldenia (Caldenal). Se distinguen tres comunidades. (22.1) Bosque xerofítico, abierto, caducifolio, dominado por Prosopis caldenia y acompañado de Prosopis flexuosa, Geoffroea decorticans y Jodina rhombifolia (Cano et al. 1980). Forma masas continuas sobre áreas medanosas al norte. En el sur está restringido a las partes bajas de los valles y la vegetación es más arbustiva en las pendientes medias y altas. (22.2) Pastizal con especies mesotérmicas, dominado por Nassella spp., Jarava spp. y Piptochaetium spp., ocupa las planicies que separan los valles. (22.3) Pastizal psamófitico de Elionurus muticus con Hyalis argentea. Ocupa áreas medanosas y onduladas.

\section{Provincia Fitogeográfica del Monte}

La vegetación poseecaracterísticas xerofíticas: plantas con hojas pequeñas, reducidas a espinas o ausentes, tallos fotosintetizantes, cobertura foliar y caulinar cerosa o resinosa, cutículas engrosadas, ciclo anual breve y órganos aéreos y subterráneos suculentos. El tipo de vegetación dominante y constante es la estepa de arbustos xerófíticos de follaje perenne (a veces caedizo en sequías extremas) y resinoso, pertenecientes en su mayoría a la familia Zigofiláceas, representados especialmente por el género Larrea (Larrea divaricata, L. cuneifolia, L. nitida y L. ameghinoi), con altura entre 1.5 y $2.5 \mathrm{~m}$, con escasez de gramíneas y árboles (Morello 1958; Roig et al. 2009). Esta estepa arbustiva zonal está asociada a suelos formados por deposiciones finas. Desde los $32^{\circ}$ de latitud hacia el norte, la provincia está asociada a serranías y bolsones con lluvias estivales. En cambio, hacia el sur está asociada a llanuras y mesetas con lluvias invernales o régimen isohigro en la porción más oriental (Morello 1958; León et al. 1998; Burkart et al. 1999; Abraham et al. 2009). Esta provincia coincide aproximadamente con la provincia del Monte definida por otros autores (Cabrera 1976; Roig et al. 2009; Morrone 2014), excepto por un área ecotonal con la Patagonia (ver Ecotono Fitogeográfico Monte-Patagonia más abajo; León et al. 1998). Las variantes de la estepa arbustiva zonal descripta, y otros tipos de vegetación menos importantes por superficie y constancia regional, algunos de ellos azonales (estepa arbustiva de halófitas y bosque abierto freatofítico o ripario), permiten distinguir las cuatro unidades que se detallan a continuación.

Unidad 23. Estepa de Zigofiláceas con Cactáceas columnares (Monte de Sierras y Bolsones). Incluye tres comunidades; las dos primeras son zonales y la tercera es azonal. (23.1) Estepa arbustiva de Larrea divaricata, L. cuneifolia, L. nitida y Parkinsonia aculeata, con un estrato arbóreo constituido por ejemplares aislados de Prosopis flexuosa (Roig 1972; Roig et al. 2009). (23.2) Estepa espinosa con Cactáceas columnares y Bromeliáceas, asociada al pedemonte. (23.3) Pastizal alto asociado a fondos de valles. Existe también un bosque abierto de ribera de Prosopis spp., de Salix humboldtiana y de Acacia visco, y una estepa arbustiva de halófitas (Morello 1958; Roig 1972; Morello et al. 2012).

Unidad 24. Estepa de Zigofiláceas y estepa de halófitas (Bolsones Endorreicos). Incluye cuatro comunidades, de las que sólo la primera es zonal. (24.1) Estepa arbustiva achaparrada y de escasa cobertura, con Larrea divaricata, L. cuneifolia, Chuquiraga erinacea, y Prosopis flexuosa como arbustiva (Roig 1972; Roig et al. 2009). Además, se desarrollan aquí comunidades azonales sobre suelos cuaternarios de origen lacustre, determinadas principalmente por la concentración de sales y la cantidad de agua disponible. Por lo general, las áreas más húmedas son las más bajas y salinas (Roig 1972). (24.2) En las partes más altas, con suelos areno-arcillosos con relativo buen drenaje, predomina el matorral halofítico con Atriplex argentina, Atriplex spegazzinii, Atriplex lampa, Suaeda divaricata, Plectrocarpa 
tetracantha, entre otras, abundantes Cactáceas y especies típicas del Monte, no características de suelos salinos (Roig 1972; Roig et al. 1996). (24.3) En las partes más bajas, con suelos arcillosos, a veces impermeables en los que se forman pantanos periódicos, el matorral tiene un estrato superior de Allenrolfea vaginata, Cyclolepis genistoides, Atriplex vulgatissima, Prosopis alpataco, y un estrato inferior de Prosopis strombulifera. (24.4) Si el período de inundación es muy prolongado dominan Baccharis spartioides, Distichlis spicata, Tessaria absinthioides, entre otras (Roig 1972).

Unidad 25. Estepa de Zigofiláceas de baja cobertura (Monte Austral o Típico). Está unidad está mayoritariamente ubicada en la mitad sur de la provincia. La comunidad zonal es la estepa arbustiva de Larrea divaricata, L. cuneifolia, Parkinsonia aculeata, L. ameghinoi (con mayor presencia hacia el sur de la unidad) y L. nitida (con mayor presencia en la parte norte) (25.1; Roig et al. 2009), que se presenta con varios estratos, muy poca cobertura, y particularmente con escasez de Cactáceas. El estrato inferior (menor a $0.5 \mathrm{~m}$ ) es de gramíneas, hierbas y arbustos bajos; presenta 10 a $20 \%$ de cobertura, que puede aumentar mucho por el crecimiento de efímeras. Los estratos bajo y medio $(0.5$ a $1.5 \mathrm{~m})$ son los de mayor cobertura, raramente superan el 40\%. El estrato superior (hasta $2 \mathrm{~m}$ ) es muy disperso (León et al. 1998). Las especies más frecuentes en las comunidades, además de las pertenecientes al género Larrea ya nombradas, corresponden a los géneros Lycium, Chuquiraga, Prosopis, Ephedra, Gutierrezia, Verbena y Baccharis (León et al. 1998; Morello et al. 2012). Desde el centro de Mendoza hacia el sur desaparecen los bosques de Prosopis (Morello et al. 2012), pero las especies arbustivas del género son aún frecuentes $(P$. alpataco y $P$. flexuosa; León et al. 1998).

Unidad 26. Matorral de Zigofiláceas con Prosopis y Geoffroea (Monte Oriental o de Transición). La estepa arbustiva zonal es la comunidad de Larrea divaricata, L. cuneifolia y Montea aphylla (26.1; Roig et al. 2009), puede tener mayor altura (1.5 a $3 \mathrm{~m})$, cobertura (50 a $80 \%$ ) y densidad que las estepas descriptas en el resto del Monte. Ocupa antiguas planicies aluviales relativamente bajas. Fisonómicamente se presenta como un matorral más o menos denso. Tiene un estrato leñoso casi continuo, bajo (2 a $2.5 \mathrm{~m}$ ), con abundantes isletas de Geoffroea decorticans e individuos aislados de Prosopis flexuosa. Se agrega Capparis atamisquea y se hacen muy abundantes Chuquiraga erinacea y Condalia microphylla (Bóo et al. 1997; León et al. 1998; Morello et al. 2012). El estrato de gramíneas tiene una mayor riqueza de especies que las otras estepas de Zigofiláceas del Monte; en particular, las gramíneas $\mathrm{C}_{4}$ cobran mayor importancia en esta unidad debido a una precipitación anual superior a $250 \mathrm{~mm}$, mayor temperatura y régimen isohigro (Paruelo and Lauenroth 1996; León et al. 1998; Paruelo et al. 1998, Abraham et al. 2009).

\section{Provincia Fitogeográfica Pampeana}

La vegetación es mayormente de gramíneas (pertenecientes a los géneros Nassella, Piptochaetium y Andropogon, entre otros) (Cabrera 1976; Soriano et al. 1991), acompañadas por dicotiledóneas herbáceas o subarbustivas y ocasionalmente leñosas (de los géneros Baccharis y Eupatorium, entre otros) (Cabrera 1976; Soriano et al. 1991). El tipo de vegetación dominante es la estepa o pseudoestepa, combinada con pradera y matorral (Vervoorst 1967; Cabrera 1976; Soriano et al. 1991; Burkart et al. 2005). Presenta un gradiente térmico y pluviométrico NE-SO que causa una variación gradual en los géneros subtropicales y templados (Perelman et al. 2001; Burkart et al. 2011).

Unidad 27. Sabana de Aristida jubata con Acacia y palmeras (Campos y Urundayzales). Tiene dos comunidades diferenciadas por limitaciones edáficas (Martínez-Crovetto 1965; van der Sluijs 1971; Pizzio and Royo Pallarés 1994). (27.1) Sabana de pastos altos con Aristida jubata sobre suelos lateríticos poco fértiles y bien drenados. El componente leñoso está conformado por Acacia spp., Astronium balansae y, en ocasiones, la palmera Butia yatay. Son comunes las leguminosas de los géneros Trifolium, Mimosa y Senna. (27.2) Pastizal dominado por Paspalum notatum, en ambientes levemente más secos que los ocupados por la comunidad 27.1. En ambas comunidades, el estrato inferior es un césped con Elionurus muticus, Aristida sp., Axonopus sp., y algunas Ciperáceas. Cabrera (1976) ubica esta unidad como parte de la provincia Paranaense, en el Distrito de los Campos. En cambio, aquí se considera parte de la provincia Pampeana por su afinidad florística con los pastizales vecinos en territorios de Brasil y Uruguay (Soriano et al. 1991).

Unidad 28. Pradera higrofítica de Andropogon lateralis (Malezales). La comunidad predominante es un pastizal cespitoso de 
Andropogon lateralis (28.1; al que ocupa áreas bajas se lo llama "malezal"). Se suele desarrollar sobre pedestales inundados con frecuencia, con un microrrelieve de lomadas de $40 \mathrm{~cm}$ separadas por microcanales de 1020 cm (van der Sluijs 1971; Carnevali 1994). Las Ciperáceas pueden conformar hasta 30\% de la cobertura total. Otras gramíneas de esta comunidad son Panicum milioides, Axonopus argentinus, Eragrostis bahiensis y especies del género Luziola (van der Sluijs 1971). En zonas aún más húmedas domina Coleataenia prionitis, mientras que en posiciones levemente más elevadas se desarrollan comunidades con Elionurus muticus como las descriptas para la unidad 27.

Unidad 29. Pastizal megatérmico con bosque en galería (Pampa Mesopotámica). Esta unidad presenta una marcada heterogeneidad edafológica, hidrológica y fisonómicoflorística; aquí convergen especies de la flora de unidades vecinas (Cabrera 1976). La vegetación característica es el pastizal, con abundancia de gramíneas subtropicales (Cabrera 1976), y también se da el bosque en galería y el matorral (Soriano et al. 1991). (29.1) Hacia el norte de la unidad existen pastizales húmedos, arbustales y bosques en galería. Los pastizales están conformados por Andropogon lateralis, Axonopus compresus, Baccharis spp., Eupatorium spp. y Eringium spp. (van der Sluijs 1971). En los bosques y matorrales se encuentran Acacia caven, Scutia buxifolia y Aloysia gratisima. (29.2) En la parte sur de la unidad, los pastizales tienen mayor presencia de géneros de gramíneas mesotérmicas, como Nassella y Piptochaetium. Hay también Paspalum dilatatum y Paspalum plicatulum, y leguminosas de los géneros Vicia y Rhynchosia. (29.3) Sobre la costa del Río Uruguay hay sabanas de Butia yatay, palmares densos, arbustales y estepas de psamófitas (Batista et al. 2014).

Unidad 30. Pseudoestepa mesofítica de Bothriochloa lagurioides y Nassella spp. (Pampa Ondulada). Tiene cuatro comunidades características; sólo la primera es zonal (Parodi 1930; León et al. 1984; Lewis et al. 1985; Burkart et al. 2005, 2011). La vegetación zonal es una Pseudoestepa mesofítica dominada por Bothriochloa lagurioides y Nassella charruana (30.1), que ocupa posiciones positivas con suelos profundos y bien drenados. Presenta tres o cuatro estratos herbáceos y riqueza elevada. Acompañan Nassella hyalina, Nassella neesiana, Piptochaetium spp., Baccharis spp. y Verbena spp. Existen tres comunidades azonales. (30.2) Pradera húmeda, frecuente en posiciones negativas con limitaciones de drenaje, con Paspalum quadrifarium, Paspalum dilatatum, Setaria parviflora y/o Sporobolus indicus, y especies de los géneros Carex, Cyperus, Juncus y Eryngium. (30.3) Estepa de halófitas, donde son conspicuas Distichlis spp., Sporobolus pyramidatus, Apium sellowianum, Heliotropium curassavicum y Pappophorum sp. Ocupa cercanías de cursos de agua y valles fluviales. (30.4) Bosque xerofítico de Celtis ehrenbergiana ("talar", Parodi 1940), en barrancas del río Paraná y del estuario del Río de la Plata, con Zanthoxylum rhoifolium, Zanthoxylum fagara, Prosopis alba, Jodina rhombifolia y Aspidosperma quebracho-blanco como acompañantes (Lewis and Collantes 1973). Al norte de la bahía de Samborombón las franjas de bosque tienen un ancho menor a $2 \mathrm{~km}$ de ancho (León et al. 1979), no cartografiables a la escala del mapa.

Unidad 31. Pseudoestepa de mesófitas con estepa de halófitas (Pampa Interior Plana). Tiene dos comunidades. (31.1) Pseudoestepa de mesófitas, zonal, en suelos profundos franco-arenosos. Abundan gramíneas como Poa ligularis, Nassella tenuisima, Nassella trichotoma, Eragrostis lugens, Elionurus muticus o Sorghastrum pellitum, y dicotiledóneas como Pfaffia gnaphaloides, Hypochaeris pampasica, Baccharis spp. u Oenothera spp. (31.2) Estepa de halófitas, azonal, en zonas planas y bajas cercanas a ambientes lénticos. Aquí abundan Distichlis spp., Hordeum pusillum, Leptochloa fusca, Puccinellia glaucescens y Juncus acutus, $\mathrm{y}$, entre las dicotiledóneas, Spergularia grandis, Lepidium spicatum, Plantago myosurus o Hypochaeris spp. Esta comunidad es similar a la decripta en la unidad 33 como estepa de halófitas (ver más abajo; Ragonese and Covas 1947; Burkart et al. 2005).

Unidad 32. Estepa psamofítica de Sorghastrum pellitum y Elionurus muticus (Pampa Interior Occidental). Incluye dos comunidades zonales asociadas a diferencias edáficas y variantes ligadas al uso pastoril (León and Marangón 1980; León and Anderson 1983; Aguilera et al. 1998). (32.1) Pseudoestepa de Sorghastrum pellitum y Elionurus muticus. Acompañan Poa ligularis, Nassella trichotoma, Bothriochloa springfieldii y Piptochaetium napostense. También son comunes las dicotiledóneas Conyza blakei, Glandularia hookeriana, Discaria spp. y Thelesperma megapotamica. (32.2) En fondos de hondonadas y cuevas de vizcachas hay una comunidad tan rica como la anterior, pero con Jarava ichu, Nassella tenuissima y Pappophorum pappiferum. Los sitios muy pastoreados tienen 
menor riqueza, e incluyen Aristida adscensionis, Nassella tenuis y Salsola kali. El límite occidental de la unidad fue modificado recientemente (Demaría et al. 2016).

Unidad 33. Praderas de higrófitas y halófitas (Pampa Deprimida). Es un complejo con seis comunidades asociadas a condiciones edáfico-topográficas (Vervoorst 1967; Lewis and Collantes 1973; León et al. 1979; Batista et al. 1988; Burkart et al. 1990, 1998; Batista and León 1992; Batista et al. 2005; Perelman et al. 2001, 2003). (33.1) Pradera de mesófitas, ocupa posiciones positivas e intermedias, con Piptochaetium stipoides, Nassella trichotoma, Paspalum dilatatum, Borreria dasycephala, Sida rhombifolia y Adesmia bicolor. (33.2) Pradera húmeda de mesófitas, en áreas planas y posiciones intermedias con suelos levemente hidromórficos, con Nassella neesiana, Piptochaetium montevidense, P. bicolor, Danthonia montevidensis y Stenotaphrum secundatum. (33.3) Pradera húmeda de higrófitas, en posiciones bajas con anegamiento prolongado y suelos ácidos. Allí abundan Solanum glaucophyllum, Glyceria multiflora, Paspalidium paludivagum, Leersia hexandra y Gratiola peruviana. (33.4) Estepa de halófitas, en posiciones bajas de áreas planas o circundantes a ambientes lénticos, con suelos salinos. Aguí se encuentran Sporobolus pyramidatus, Hainardia cylindrica, Hordeum stenostachys y Lepidium parodii. (33.5) Estepa húmeda de halófitas, en posiciones negativas de valles fluviales, con suelos hidro y halomórficos. Aquí se encuentran Spartina densiflora, Sesuvium portulacastrum y Sarcocornia ambigua. (33.6) Bosque xerofítico de Celtis ehrenbergiana ("talar", Parodi 1940; ver también el bosque 30.4 descripto más arriba), ocupa suelos sueltos y permeables asociados a cordones de depósitos calcáreos de conchillas paralelos a la costa Atlántica. Puede estar codominado por Scutia buxifolia o Colletia paradoxa, y acompañado por Jodina rhombifolia, Schinus longifolius, Sambucus australis y Phytolacca dioica (Vervoorst 1967; Lewis and Collantes 1973).

Unidad 34. Pseudoestepa de mesófitas con matorral serrano (Pampa Austral). Esta unidad presenta marcada heterogeneidad asociada a la presencia y profundidad de tosca o existencia de rocas. Se diferencian groseramente dos comunidades (Frangi 1975; Frangi and Bottino 1995). (34.1) Pseudoestepa de mesófitas, zonal, estratificada, rica en especies de los géneros Nassella, Piptochaetium, Melica, Briza y Danthonia. Las más abundantes son Nassella neesiana, N. trichotoma, Piptochaetium napostense,
P. montevidense y Poa ligularis. (34.2) Estepa arbustiva, azonal, que ocupa comúnmente laderas serranas y cerros rocosos. Presenta un estrato arbustivo de hasta $1 \mathrm{~m}$ de altura, con Baccharis tandilensis, B. articulata, Colletia paradoxa, Discaria longispina, y gramíneas como las de la comunidad zonal 33.1. Hay también pastizales de Paspalum quadrifarium y Cortaderia selloana. El complejo serrano Tandilia-Ventania conformaría un ecosistema de características propias (Kristensen and Frangi 1995), para el cual aún no se dispone de un mapa de vegetación (Lizzi et al. 2007).

\section{Provincia Fitogeográfica Puneña}

Ocupa mesetas y montañas entre 3400 y 4400 m s.n.m. en el noroeste del país, y entre 2000 y 2600 m s.n.m. en Mendoza (Cabrera 1976; Martínez Carretero 1995). En general, se trata de áreas que confluyen en cuencas endorreicas. La vegetación presenta adaptaciones a la falta de agua durante gran parte del año, a las bajas temperaturas y al pastoreo, como raíces profundas (Adesmia schickendanzii), tejidos de almacenamiento de agua (Tephrocactus spp.), hojas pequeñas o tallos fotosintéticos (Fabiana denudata), espinas (Aloysia salsoloides), o plantas en cojín o placa a ras del suelo (Werneria aretioides, Azorella compacta) (Ruthsatz and Movia 1975). El tipo de vegetación característico es la estepa arbustiva baja, con un marcado gradiente NE-SO de disminución de la cobertura vegetal y la diversidad, que se relaciona con la disminución de la precipitación media anual de $350 \mathrm{~mm}$ en el NE hasta menos de $50 \mathrm{~mm}$ en el SO (Cabrera 1976; Martínez Carretero 1995; Baldassini et al. 2012).

Unidad 35. Estepa de Fabiana densa y Baccharis boliviensis (Puna). La estepa de Fabiana densa y Baccharis boliviensis (35.1) es la comunidad más extendida en la provincia, con arbustos de 40-60 cm de altura y escasa cobertura de hierbas, con presencia también de otras especies arbustivas como Adesmia horrida, Aloysia salsoloides y Tetraglochin cristatum. Además, existen especies endémicas en la porción más húmeda del NE, como Mutisia saltensis, Chersodoma argentina, Nassella arcuata o Nototriche pygmaea, y otras en la porción más seca del SO, como Senecio uspallatensis, Chuquiraga echegarayi, Aphyllocladus sanmartinianus o Pappostipa nicorae (Martínez Carretero 1995). Existe, además, una estepa graminosa (35.2) en las zonas más elevadas y numerosas comunidades azonales (e.g., estepa de halófitas, estepa de psamófitas, vega, 
entre otras). En la puna de Jujuy hay también bosquecitos de la única especie arbórea de la provincia fitogeográfica, Polylepis tomentella (Cabrera 1976; Renison et al. 2013).

\section{Provincia Fitogeográfica Altoandina}

Ocupa las altas cumbres de la cordillera de los Andes, por encima de 4400 m s.n.m. en Jujuy y de 500 m s.n.m. en Tierra del Fuego (Roig 1972; Cabrera 1976; Morello et al. 2012). La vegetación es una combinación de especies con características asociadas al xerofitismo extremo, a las bajas temperaturas y al viento. Las gramíneas forman matas aisladas, bajas y compactas, circulares o semilunares. Las dicotiledóneas se caracterizan por un gran desarrollo subterráneo, hojas pequeñas, presencia de resinas, estomas protegidos y tricomas. Son frecuentes los arbustos rastreros y las plantas en cojín o en placas adosadas al suelo (Cabrera 1976). En laderas rocosas las plantas crecen sometidas a deslizamientos de material por gravedad, lo que suele determinar que los órganos subterráneos queden ubicados en una posición relativa más alta que los aéreos. Es probablemente la provincia fitogeográfica menos conocida desde el punto de vista de la vegetación. Resta aún una caracterización fisonómico-florística más acabada (e.g., ver Ferreyra et al. 1998), que permitiría distinguir entre los sectores boreal, central y austral. Aquí se identifica una unidad que se describe a continuación.

Unidad 36. Estepa baja de Senecio algens y Oxalis compacta (provincia Altoandina). La vegetación zonal predominante consiste en una estepa de caméfitas y hemicriptófitas herbáceas (36.1), con una composición muy heterogénea que depende de la latitud, la altura, la exposición, el nivel de humedad y el suelo. Suelen ser constantes Senecio algens en manchones densos y Oxalis compacta, que forma cojines, con Jaborosa laciniata, Nastanthus ventosus, Calandrinia spp. Existe también una estepa graminosa (36.2) muy abierta, dehasta 40 cm de altura, representada por una asociación de Festuca orthophylla, Festuca chrysophylla, Poa gymnantha, Stipa speciosa o Pappostipa vaginata, con varias especies acompañantes cespitosas como Pappostipa frigida, Nassella mucronata, Deyeuxia cabrerae, etc. Otros tipos de vegetación zonal también presentes son la estepa arbustiva y el semidesierto de líquenes, y, como azonal, la vega de Poáceas, Juncáceas y Ciperáceas (Cabrera 1976; Wingenroth and Suárez 1984; Morello et al. 2012). Para esta unidad se han descripto recientemente dos clases de vegetación, que reunirían a varias comunidades (Martínez Carretero et al. 2016).

\section{Provincia Fitogeográfica Patagónica}

La vegetación típica es la estepa, con numerosas variantes que dependen de la abundancia relativa de gramíneas y arbustos. La cobertura varía desde casi nula en áreas con precipitación anual menor a 200 mm y con mayor deterioro antrópico, hasta más de $80 \%$ en áreas con 450 mm o más. Son frecuentes las especies con adaptaciones a la sequía y a la herbivoría, como arbustos áfilos o con hojas pequeñas (Ephedra ochreata), espinosos, gramíneas cespitosas (Pappostipa spp.) y arbustos semiesféricos laxos (Mulinum spinosum) o en cojines compactos (Brachyclados caespitosum) (Cabrera 1976; León et al. 1998; Golluscio et al. 2011; Damascos et al. 2008).

Unidad 37. Estepa arbustiva con Ephedra ocreata o Chuquiraga rosulata (Distrito de la Payunia). Esta unidad se ubica sobre suelos permeables de arena volcánica que resulta en condiciones de aridez para la vegetación. La vegetación típica es una mezcla de estepa graminosa con baja cobertura de Sporobolus rigens, Panicum urvilleanum o Pappostipa speciosa (37.1), y matorral de Ephedra ocreata, Mulinum spinosum, Stillingia patagonica, Anarthrophyllum rigidum, Neosparton aphyllum y Grindelia chiloensis (37.2; Cabrera 1976; Candia et al. 1993). En esta unidad existen también matorrales dominados por Chuquiraga rosulata, Prosopis denudans, Schinus polygamus (37.3; León et al. 1998). Esta unidad posee un alto número de especies endémicas, como Berberis comberi, Condalia megacarpa, Prosopis castellanosii y Senna kurtzii.

Unidad 38. Estepa graminosa de Festuca pallescens (Distrito Subandino; Estepa de coirón blanco). Se encuentra en áreas con precipitación anual entre 300 y $600 \mathrm{~mm}$ e ingresa en el sector oriental del bosque caducifolio (50.1; ver más abajo) en un amplio ecotono en forma de parches o mosaicos, con suelos relativamente ricos de materia orgánica y con buena capacidad de retención hídrica. La vegetación típica es una estepa graminosa (38.1) con alta cobertura (64\% en promedio), dominada por Festuca pallescens y acompañada por Rytidosperma pictum, Lathyrus magellanicus y unos pocos arbustos bajos dispersos (Senecio sericeonitens, Mulinum spinosum; Soriano 1956; Golluscio et al. 1982). Otras gramíneas que dan valor forrajero a esta comunidad (38.1), 
aunque se presentan con baja cobertura, son Festuca magellanica, Festuca pyrogea, Avenella flexuosa, Phleum alpinum, Elymus patagonicus y Rytidosperma virescens (León et al. 1998).

Unidad 39. Estepa arbustivo graminosa (Distrito Occidental). Se encuentra en áreas con precipitación anual entre 200 y 300 mm. La vegetación típica es una estepa dominada por las gramíneas Pappostipa speciosa, Pappostipa humilis, Poa ligularis y Poa lanuginosa, y los arbustos Adesmia volckmannii y Berberis microphylla, que alcanzan entre 60 y $180 \mathrm{~cm}$ de altura (39.1; Golluscio et al. 1982). Tiene numerosas variantes según la abundancia de otras especies acompañantes que pueden ser localmente abundantes, como los arbustos Mulinum spinosum, Senecio filaginoides, Grindelia anethifolia, Nassauvia glomerulosa, Nassauvia axillaris, Retanilla patagonica, Ephedra frustillata, Colliguaja integerrima, Junellia tonini var. mulinoides, o las gramíneas Jarava neaei, Bromus setifolius o Poa huecu (León et al. 1998, Cingolani et al. 2000). Parte de esta unidad se ubica en la meseta de Somuncurá, una formación basáltica que supera los $1200 \mathrm{~m}$ s.n.m. y que es notable por sus endemismos, entre ellos Grindelia pygmaea, Senecio chipauquilensis, Senecio mustersii var. dentatus, Adesmia serrana y Lecanophora ruiz-leali.

Unidad 40. Estepa arbustiva con Chuquiraga avellanedae (Distrito Central; Estepa arbustiva de quilenbai). Esta estepa arbustiva (40.1) presenta una cobertura de entre 30 y 50\% y dos estratos, el inferior de hasta $20 \mathrm{~cm}$ y el superior de hasta $1 \mathrm{~m}$. En el estrato inferior se encuentran Acantholippia seriphioides, Nassauvia ulicina, N. glomerulosa, Pleurophora patagonica, Acaena platyacantha, Pappostipa humilis, P. speciosa, Jarava neaei, Poa lanuginosa, $P$. ligularis, entre otras. En el superior domina Chuquiraga avellanedae, con Lycium ameghinoi, Lycium chilense, Mulguraea ligustrina, Prosopis denudans y Schinus polygamus.

Unidad 41. Estepa arbustiva serrana con Colliguaja integerrima (Distrito Central; Estepa arbustiva serrana). Esta unidad se ubica en áreas serranas del centro de Chubut y está caracterizada por una estepa arbustiva de 1.70 m de altura (41.1), dominada por Colliguaja integerrima acompañada por Mulguraea tridens, Mulguraea ligustrina, Adesmia boronioides, Schinus polygamus, Lycium chilense, Berberis microphylla, Nardophyllum bryoides, Anarthrophyllum rigidum, Anarthrophyllum desideratum y Neobaclea crispifolia.

Unidad 42. Estepa arbustiva baja (Distrito Central; Erial). Es la unidad con mayor superficie en la provincia. Está formada por una estepa con arbustos bajos en cojín y unas pocas gramíneas, en conjunto no cubren más del 50\% del suelo (León et al. 1998). Existen numerosas variantes de esta unidad dependiendo de las especies dominantes: (42.1) Nassauvia glomerulosa, N. ulicina o Chuquiraga aurea, a las que acompañan Chuquiraga avellanedae, Ch. morenonis, Hoffmannseggia trifoliata, Acantholippia seriphioides, Brachyclados caespitosus, Pappostipa humilis, Pappostipa ibarii y Pappostipa ameghinoi, entre otras (Bertiller et al. 1981a; Golluscio et al. 1982). Hacia el sur de esta unidad, las estepas estarían degradadas y se agregan algunas especies a las dominantes ya citadas como Petunia patagonica, Poa spiciformis, Azorella trifurcata y Mulinum microphyllum (42.2). En áreas medanosas dominan Prosopis denudans y Lycium chilense junto con Atriplex sagittifolia, Senecio filaginoides o Sporobolus rigens (Bertiller et al. 1981a).

Unidad 43. Estepa arbustiva alta y graminoso arbustiva (Distrito del Golfo San Jorge). La vegetación de esta unidad incluye dos tipos fisonómicos principales (Cabrera 1976; León et al. 1998). En las laderas de las mesetas que se orientan al Golfo San Jorge se encuentran estepas arbustivas altas dominadas por Colliguaja integerrima (43.1). Estas estepas alcanzan los $80 \mathrm{~cm}$ de altura si los arbustos acompañantes son Senecio filaginoides, Grindelia chiloensis, Baccharis darwinii, Nassauvia ulicina y los pastos Pappostipa humilis, Poa lanuginosa, Poa ligularis o Festuca argentina. Otras estepas arbustivas alcanzan los $2 \mathrm{~m}$ de altura si los arbustos que acompañan a Colliguaja integerrima son Retanilla patagonica o Acantholippia seriphioides, y en un estrato más bajo Acaena platyacantha, Senecio bracteolatus, Festuca argentina, Jarava neaei, Phacelia secunda o el arbusto rastrero Larrea ameghinoi (43.2). Por otro lado, en las áreas planas y elevadas de las mesetas aparecen estepas de gramíneas con arbustos dispersos, con una cobertura de $80 \%$ (43.3). Las gramíneas dominantes son Festuca pallescens, Festuca argentina y Pappostipa speciosa, con los arbustos Senecio filaginoides, Nardophyllum bryoides, Mulinum spinosum, Adesmia volckmannii, Junellia thymifolia y Acaena platyacantha, entre otros (León et al. 1998; Bertolami et al. 2008).

Unidad 44. Estepa arbustiva baja con Nardophyllum bryoides (Distrito Central). Es una estepa baja dominada por el arbusto con forma de cojín de hasta $1 \mathrm{~m}$ de altura Nardophyllum bryoides, acompañado por Festuca pallescens (44.1; León et al. 1998). 
Ocupa las mesetas y sierras cercanas a los lagos Stroebel y Cardiel.

Unidad 45. Estepa arbustiva baja con Mulguraea tridens (Distrito Central; Estepa arbustiva de mata negra). Es una estepa arbustiva con una cobertura de $60 \%$, dominada por el arbusto Mulguraea tridens que alcanza una altura de $70 \mathrm{~cm}$ (45.1; León et al. 1998). El estrato herbáceo es escaso, con Pappostipa ibarii, Jarava neaei, Pappostipa speciosa, Festuca pyrogea, Nassauvia darwinii, Acaena poeppigiana y Azorella trifurcata. Se encuentra en las mesetas al norte y al sur del valle del río Santa Cruz.

Unidad 46. Estepa graminosa seca de Festuca gracillima (Distrito Subandino; Estepa magallánica seca). Se encuentra en áreas con precipitación anual entre 200 y 300 mm, en la cuenca baja del río Gallegos. La comunidad típica (46.1) es la estepa graminosa con una cobertura de hasta $80 \%$, dominada por Festuca gracillima, que forma matas de $30-40 \mathrm{~cm}$ de altura (Roig et al. 1985). Entre estas matas se encuentran otras gramíneas o hierbas pequeñas como Rytidosperma virescens, Carex andina, Viola maculata, Calceolaria uniflora, Azorella fuegiana.

Unidad 47. Estepa graminosa húmeda de Festuca gracillima (Unidad 47; Distrito Fueguino; Estepa magallánica húmeda). Esta estepa se encuentra en el extremo sur de la provincia, en áreas con precipitación anual de entre 300 y $450 \mathrm{~mm}$. Las especies dominantes son la gramínea Festuca gracillima y los arbustos Empetrum rubrum y Chiliotrichum diffusum. La abundancia relativa de estas especies varía, originando diferentes comunidades (Collantes et al. 1999). En suelos ácidos a ligeramente ácidos se encuentran las comunidades con Empetrum rubrum (47.1); son frecuentes las estepas de Empetrum rubrum y Festuca gracillima, con Avenella flexuosa, Anthoxanthum pusillum, Poa alopecurus, Gentianella magellanica, Senecio magellanicus, Primula magellanica, o los matorrales dominados por Empetrum rubrum o por Chiliotrichum diffusum. En suelos más neutros se encuentran las comunidades sin Empetrum rubrum (47.2). Entre estas comunidades dominan los matorrales densos de Chiliotrichum diffusum acompañado de otros arbustos como Berberis microphylla y Ribes magellanicum, o las estepas graminosas de Festuca gracillima con Poa sp.

\section{Ecotono Fitogeográfico Monte-Patagonia}

La transición entre las provincias Patagónica y del Monte se produce de una manera gradual, en especial en aquellas áreas en donde no existen discontinuidades geomorfológicas que determinen cambios altitudinales importantes (Cabrera 1947). La zona de transición corresponde al límite austral de influencia del Océano Atlántico, donde ocurre un cambio climático gradual (mayor amplitud térmica y menor concentración invernal de las precipitaciones), cuyo límite fluctúa de año a año. Esto contribuiría a generar áreas ecotonales, en cuanto a estructura y composición florística, en las que coexisten elementos típicos de ambas provincias. Se señala la existencia de dos unidades geográficamente disyuntas (León et al. 1998).

Unidad 48. Estepa arbustiva ecotonal con Prosopis denudans (Ecotono Rionegrino). Ocupa principalmente un paisaje de peniplanicies, entre 300 y 600 m s.n.m., que se extiende en el centro-sur de Río Negro, entre las sierras y mesetas y las antiguas planicies aluviales. También ocupa los niveles más bajos de la meseta de Somuncurá. Presenta una fisonomía intermedia entre el típico matorral del Monte y las estepas patagónicas. La cobertura vegetal total varía entre 30 y 50\%. En general, se encuentra un estrato arbustivo abierto de 1 a 1.5 m de altura en el que predominan arbustos del Monte (48.1), principalmente Prosopis denudans, Schinus polygamus, Larrea nitida, Prosopidastrum globosum, Bougainvillea spinosa y Verbena sp., muchas veces agrupados formando isletas. Debajo se desarrolla un estrato de arbustos bajos y gramíneas cespitosas, de características netamente patagónicas: Mulinum spinosum, Senecio filaginoides, Grindelia chiloensis, Nassauvia glomerulosa, Tetraglochin ameghinoi, Chuquiraga avellanedae, Pappostipa humilis y $P$. speciosa (Ruiz Leal 1972; Beeskow et al. 1982; Speck 1982; Bran et al. 1991).

Unidad 49. Estepa arbustiva ecotonal con Chuquiraga avellanedae (Ecotono de la Península de Valdés). Ocupa la Península de Valdés, incluyendo el Istmo Ameghino (Morello et al. 2012). El paisaje general es el de una planicie que presenta dos áreas deprimidas con salinas, y cordones medanosos en el tercio austral. La vegetación es una estepa arbustiva de 0.5 a 1.5 m de altura (49.1), dominada por Chuquiraga avellanedae, Chuquiraga erinacea y Condalia microphylla, y en menor medida por Brachyclados megalanthus, Lycium chilense, Schinus polygamus, Prosopidastrum globosum y Larrea nitida. Las gramíneas más abundantes son Nassella tenuis, Nassella longiglumis, Pappostipa speciosa, Piptochaetium napostaense 
y Poa ligularis. Las hierbas son escasas. La cobertura vegetal total es 40 a 60\%, levemente más alta que en el área continental (Bertiller et al. 1981b). En los cordones medanosos se desarrollan (49.2) estepas graminosas con Sporobolus rigens, Nassella tenuis, Panicum urvilleanum, Poa lanuginosa y Piptochaetium napostaense. Entre las no gramíneas, las más comunes son Hyalis argentea y Chuquiraga avellanedae. La cobertura vegetal total es 60 a $80 \%$, correspondiendo a las no gramíneas entre 10 y $30 \%$.

\section{Provincia Fitogeográfica Subantártica}

Esta provincia se restringe en la Argentina a una franja muy angosta e interrumpida. La vegetación zonal está representada por la selva templada y el bosque caducifolio, perennifolio o mixto; hay también matorral de altura. Predominan las especies con hojas de tamaño mediano a pequeño o escamiformes. Tanto en el bosque como en la selva dominan especies endémicas de los géneros Nothofagus, Austrocedrus, Fitzroya, entre otros. Es la única provincia del país que presenta extensas áreas cubiertas por turberas, que constituyen vegetación azonal (Dimitri 1962; Cabrera and Willink 1973; Cabrera 1976).

Unidad 50. Bosque caducifolio de Nothofagus spp. y Selva pluvial templada (Bosques Andino-Patagónicos). El bosque caducifolio más constante es el de Nothofagus pumilio y $N$. antarctica (50.1), que se extiende desde los $37.8^{\circ} \mathrm{S}$ hacia el sur. Desde la latitud indicada y hasta los $40^{\circ} \mathrm{S}$ incluye también a Araucaria araucana como acompañante (entre 900 y 1800 m s.n.m.; hay también bosques puros de A. Araucana) (Cabrera 1976). Hasta los $47^{\circ}$ $\mathrm{S}$ aparecen también bosques de Nothofagus alpina, N. dombeyi, N. obliqua o Austrocedrus chilensis. La porción florísticamente más rica corresponde al sur de Neuquén, Río Negro y norte de Chubut. A las especies listadas se suman Lomatia hirsuta subsp. obliqua, Maytenus boaria, Schinus patagonicus, y las arbustivas Azara microphylla, Aristotelia chilensis, Chusquea culeou y varias del género Berberis. La selva pluvial templada (50.2; "selva valdiviana") (Hauman 1916) sólo está presente en la Argentina aproximadamente a 600 m s.n.m., con una precipitación media anual que puede superar los $4000 \mathrm{~mm}$, en las orillas de lagos o valles transversales que desaguan en el océano Pacífico (Lago Futalaufquen, oeste del Lago Puelo, Brazo Blest del Lago Nahuel Huapi y Laguna Frías). En sus sitios más representativos alcanza una altura de $40 \mathrm{~m}$ y una cobertura de $100 \%$, presenta múltiples estratos y tiene un buen número de especies fanerófitas trepadoras, pteridófitas, briófitas y talófitas. La especie más frecuente es $N$. dombeyi (Dimitri 1962; Cabrera 1976).

\section{COMENTARIO FINAL}

El mapa puede ser útil para los interesados en conocer la vegetación espontánea de la Argentina, la actual o la que fue reemplazada, e inferir a través de ella tanto áreas con cierta homogeneidad como patrones espaciales heterogéneos. El mapa también puede ser útil para evaluar el potencial de los recursos florísticos de una región y servir de base para estudios de vegetación a través de regiones, gradientes y/o ecotonos. Sintetiza el trabajo de más de tres generaciones de botánicos y ecólogos. Las similitudes y las diferencias entre los límites aquí presentados y los hallables en intentos de similar escala cartográfica, como el mapa de ecorregiones y complejos ecosistémicos de Morello et al. (2012) o el mapa de suelos de la Argentina (INTA 1990), pueden ser tema de fructíferas investigaciones por venir.

Agradecimientos. En homenaje a la memoria del querido mentor y maestro, Dr. Rolando León (1932-2015), quien directa o indirectamente nos enseñó a observar y describir la heterogeneidad de la vegetación. El CONICET patrocinó a Mariano Oyarzabal mediante una beca posdoctoral. Este trabajo fue financiado parcialmente por la Agencia Nacional de Promoción Científica y Tecnológica y la Universidad de Buenos Aires. Mucho agradecemos la colaboración de Gonzalo Camba Sans, Facundo Della Nave y Lautaro Grande Pastorini para elaborar y manejar el archivo vectorial. Germán Baldi, Ana Cingolani y un revisor anónimo hicieron correcciones y comentarios muy valiosos que redundaron en una sustancial mejora del trabajo. Un mapa preliminar que dio origen a este manuscrito surgió de un proyecto conjunto entre la Asociación Argentina de Consorcios Regionales de Experimentación Agrícola (AACREA), la Facultad de Agronomía de la Universidad de Buenos Aires (FAUBA), el Instituto Nacional de Tecnología Agropecuaria (INTA) y el Ministerio de Agricultura, Ganadería y Pesca de la Nación (MAGyP), financiado por el Instituto de Promoción de la Carne Vacuna Argentina (IPCVA). Agradecemos especialmente los aportes de Lisandro Blanco, Cristian Feldkamp y Claudio Hofer durante esa etapa. 


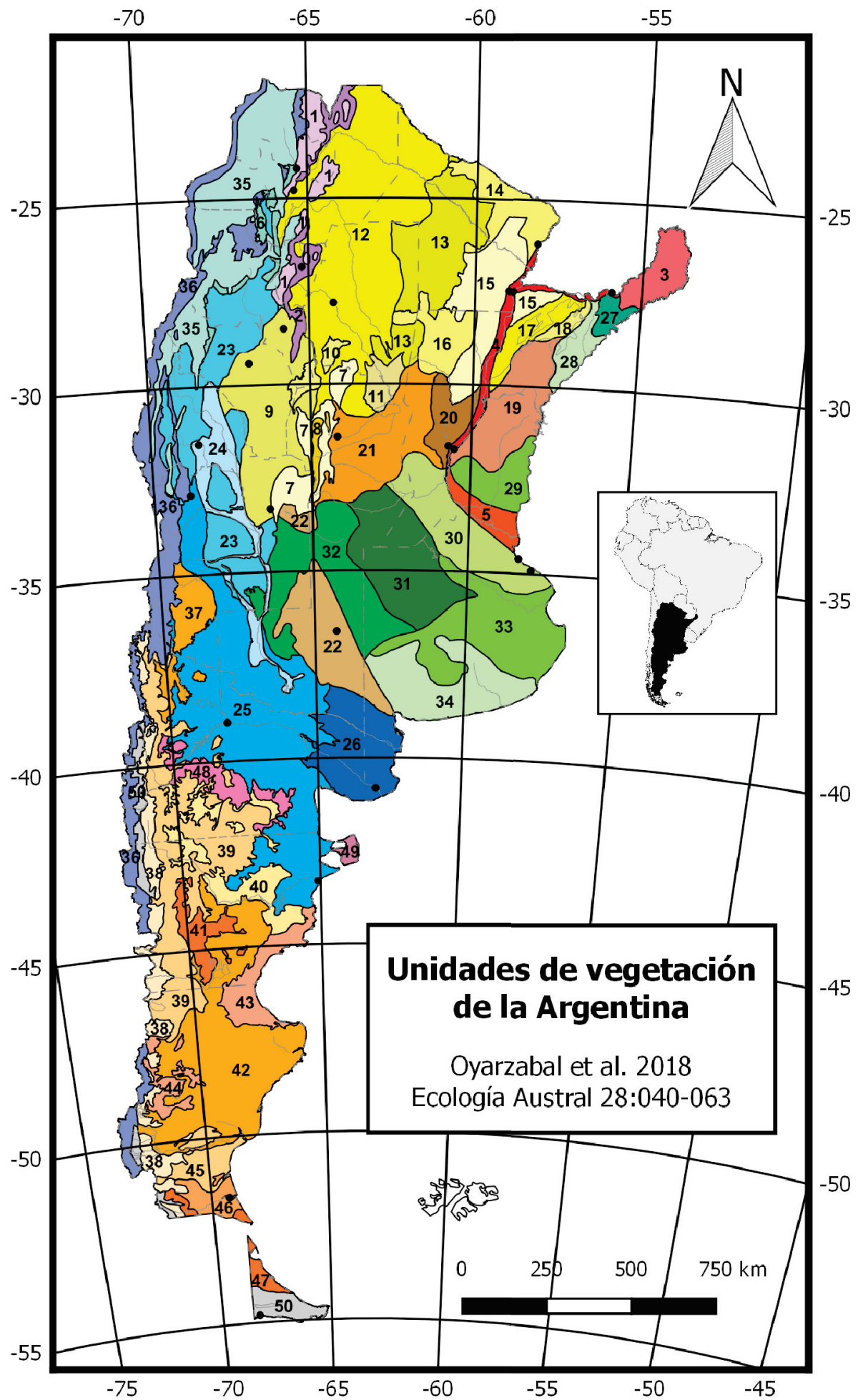

Figura 1. Unidades de vegetación de la Argentina agrupadas en provincias y ecotonos fitogeográficos, dominios y regiones. Se indican los nombres fisonómico-florísticos propuestos y los nombres populares o más conocidos. Las líneas grises punteadas corresponden a los límites de las provincias políticas y las llenas a los principales ríos. Los círculos negros indican las ciudades capitales.

Figure 1. Vegetation units of Argentina as subdivisions of phytogeographic provinces and ecotones, domains and regions. Proposed physiognomic-floristic and popular or best-known names are indicated. Grey discontinuous lines correspond to the boundaries of political provinces and solid lines to the main rivers. Black circles indicate capital cities. 


\section{Nombre fisonómico-florístico}

Región Neotropical

Dominio Amazónico

Provincia Fitogeográfica de las Yungas

Provincia Fitogeográfica Paranaense

\section{Dominio Chaqueño}

Provincia Fitogeográfica Prepuneña

Provincia Fitogeográfica Chaqueña

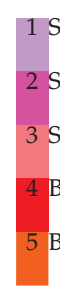

Selva y Bosque montanos

Selva pluvial semicaducifolia

Bosque ribereño subtropical

Bosque y humedal deltaicos
Provincia Fitogeográfica Pampeana
Provincia Fitogeográfica del Espinal

Provincia Fitogeográfica del Monte
Selva pluvial semicaducifolia pedemontana

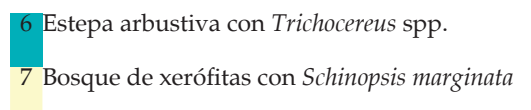

8 Pastizal de Stipeas y Festuceas

9 Bosque de xerófitas con Aspidosperma quebracho-blanco en transición a estepa

10 Matorral de halófitas

11 Pastizal y Matorral de halófitas

12 Bosque de xerófitas con Schinopsis lorentzii

13 Bosque de xerófitas con Schinopsis balansae y Schinopsis lorentzii, y Pastizal

14 Sabana de Copernicia alba y Sorghastrum setosum, y Mosaico Chaco Húmedo con Bosques, Pajonales y de Bosques

15 Mosaico de Bosque de xerófitas, de mesófitas, Sabana y Selva de albardón

16 Pastizal de Spartina spartinae

17 Sabana de Andropogon lateralis y Paspalum notatum

18 Mosaico de comunidades higrófiticas

19 Bosque de esclerófitas con Prosopis affinis

Bosque de esclerófitas con Prosopis nigra y Acacia caven

21 Bosque de esclerófitas con Prosopis nigra y Prosopis alba

22 Bosque de esclerófitas con Prosopis caldenia

23 Estepa de Zigofiláceas con Cactáceas columnares

24 Estepa de Zigofiláceas y estepa de halófitas

5 Estepa de Zigofiláceas de baja cobertura

Matorral de Zigofiláceas con Prosopis y Geoffroea

7 Sabana de Aristida jubata con Acacia y palmeras

28 Pradera higrofítica de Andropogon lateralis

29 Pastizal megatérmico con bosque en galería

30 Pseudoestepa mesofítica de Bothriochloa lagurioides y Nassella spp.

31 Pseudoestepa de mesófitas con estepa de halófitas

Estepa psamofítica de Sorghastrum pellitum y Elionurus muticus

33 Praderas de higrófitas y halófitas

34 Pseudoestepa de mesófitas con matorral serrano

Dominio Andino Patagónico

Provincia Fitogeográfica

Puneña

Provincia Fitogeográfica

Altoandina

\section{Nombre popular}

Selva Montana y Bosque de Aliso y Pino

del cerro

Selva de Transición

Selva Misionera; Selva Paranaense

Valle del Paraná

Delta del Paraná

Prepuna

Chaco Serrano

Pastizales de Altura

Chaco Árido

Bañados de Mar Chiquita; Espartillares y zampales

Chaco Semiárido

Chaco Subhúmedo

Palmares de Caranday

Chaco Húmedo con Bosques y Cañadas

Bajos Submeridionales; Espartillares

Pajonales y Palmares de Yatay

Esteros del Iberá

Nandubayzal y Selva de Montiel

Espinillar

Algarrobal

Caldenal

Monte de Sierras y Bolsones

Bolsones Endorreicos

Monte Austral o Típico

Monte Oriental o de Transición

Campos y Urundayzales

Malezales

Pampa Mesopotámica

Pampa Ondulada

Pampa Interior Plana

Pampa Interior Occidental

Pampa Deprimida

Pampa Austral

Puna

Provincia Altoandina
Salinas Grandes 
Provincia Fitogeográfica Patagónica

Ecotono Fitogeográfico Monte-Patagonia

Región Antártica

Dominio Subantártico

Provincia Fitogeográfica

Subantártica

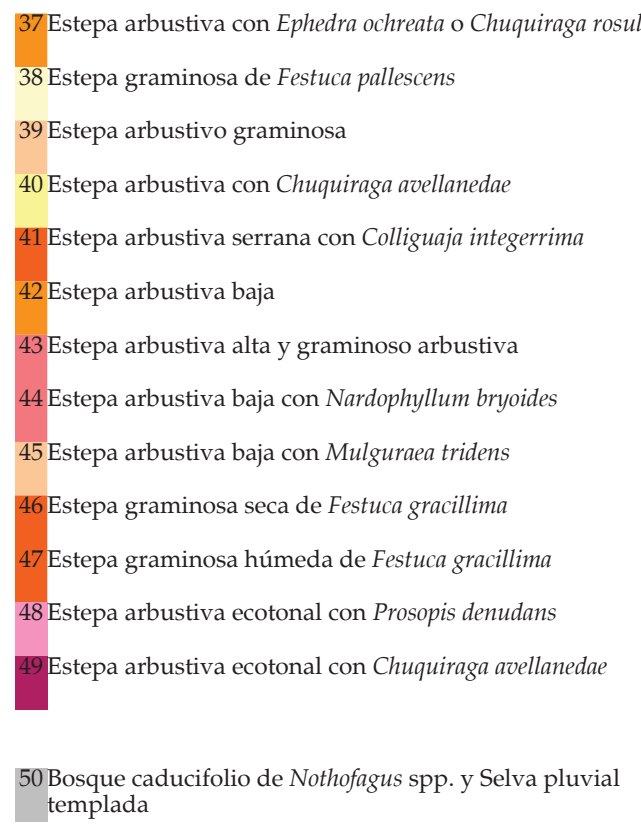

Distrito Subandino; Estepa de coirón blanco

Distrito Occidental

Distrito Central; Estepa arbustiva de quilenbai

Distrito Central; Estepa arbustiva serrana

Distrito Central; Erial

Distrito del Golfo San Jorge

Distrito Central

Distrito Central; Estepa arbustiva de mata negra

Distrito Subandino; Estepa magallánica

seca

Distrito Fueguino; Estepa magallánica

húmeda

Ecotono Rionegrino

Ecotono de la Península de Valdés

Bosques Andino-Patagónicos

\section{REFERENCIAS}

Aagesen, L., M. J. Bena, S. Nomdedeu, A. Panizza, R. P. López, and F. O. Zuloaga. 2012. Areas of endemism in the southern central Andes. Darwiniana 50:218-251.

Aagesen, L., C. A. Szumik, F. O. Zuloaga and O. Morrone. 2009. Quantitative biogeography in the South America highlands - recognizing the Altoandina, Puna and Prepuna through the study of Poaceae. Cladistics 25:295-310.

Abraham, E., H. F. del Valle, F. Roig, L. Torres, J. O. Ares, F. Coronato, and R. Godagnone. 2009. Overview of the geography of the Monte Desert biome (Argentina). Journal of Arid Environments 73:144-153.

Aguilera, M. O., D. F. Steinaker, M. R. Demaría, and A. O. Ávila. 1998. Estados y transiciones de los pastizales de Sorghastrum pellitum del área medanosa central de San Luis, Argentina. Ecotropicos 11(2):107-120.

Anderson, D. L., J. A. Del Águila, and A. E. Bernardón. 1970. Las formaciones vegetales en la provincia de San Luis. Rev. Inv. Agropecuaria, INTA, serie 2. Biología y Producción Vegetal 7:153-183.

Anderson, D. L., E. L. Orionte, and J. C. Vera. 1978. Una reliquia del pastizal de San Luis. Ecología 3:139-153.

Aragón, R., J. Carilla, and L. Cristobal. 2005. Fire, plant species richness and aerial biomass distribution in mountain grasslands of Northwest Argentina. Pp. 89-99 en E. Spehn, M. Liberman and C. Körner (eds.). Land Use Changes and Mountain Biodiversity. CRC Press LLC, Boca Raton FL, USA.

Baldassini, P., J. N. Volante, L. M. Califano, and J. M. Paruelo. 2012. Caracterización regional de la estructura y de la productividad de la vegetación de la Puna mediante el uso de imágenes MODIS. Ecología Austral 22:22-32.

Batista, W. B., and R. J. C. León. 1992. Asociación entre comunidades vegetales y algunas propiedades del suelo en el centro de la Depresión del Salado. Ecología Austral 2:47-55.

Batista, W. B., R. J. C. León, and S. B. Perelman. 1988. Las comunidades vegetales de un pastizal natural de la región de Laprida, Prov. de Buenos Aires, Argentina. Phytocoenologia 16(4):519-534.

Batista, W. B., A. G. Rolhauser, F. Biganzoli, S. E. Burkart, L. Goveto, A. Maranta, G. Pignataro, N. S. Morandeira, and M. Rabadán. 2014. Las comunidades vegetales de la sabana del Parque Nacional El Palmar (Argentina). Darwiniana, nueva serie 2(1):5-38.

Batista, W. B., M. A. Taboada, R. S. Lavado, S. B. Perelman, and R. J. C. León. 2005. Asociación entre comunidades vegetales y suelos en el pastizal de la Pampa Deprimida. Pp. 113-129 en M. Oesterheld, M. R. Aguiar, C. M. Ghersa and J. M. Paruelo (eds.). La heterogeneidad de la vegetación de los agroecosistemas. Un homenaje a Rolando J. C. León. Editorial Facultad de Agronomía, UBA, Buenos Aires, Argentina.

Beeskow, A. M., C. Beltramone, and H. F. Del Valle. 1982. Relevamiento fisiográfico expeditivo de la meseta de Somuncurá. Contribución Nro. 66. Centro Nacional Patagónico, CONICET, Pto. Madryn. Pp. 12.

Bertiller, M. B., A. M. Beeskow, and M. P. Irisarri. 1981a. Caracteres fisonómicos y florísticos de la vegetación del Chubut. 1. Sierra San Bernardo. Contribución Nro. 40. Centro Nacional Patagónico, CONICET, Pto. Madryn. Pp. 26.

Bertiller, M. B., A. M. Beeskow, and M. P. Irisarri. 1981b. Características florísticas y fisonómicas de la vegetación del Chubut. 2. La Península de Valdés e Istmo F. Ameghino. Contribución Nro. 41. Centro Nacional Patagónico, CONICET, Pto Madryn. Pp. 20.

Bertolami, M. A., B. L. Rueter, and M. Benítez. 2008. Análisis de espectros biológicos ponderados en pampas del sudeste de la provincia de Chubut. Multequina 17:93-107.

Boelcke, O., D. M. Moore, and F. A. Roig. 1985. Transecta Botánica de la Patagonia Austral. CONICET (Argentina), 
Royal Society (UK) e Instituto de la Patagonia (Chile). Pp. 733.

Bóo, R. M., D. V. Peláez, S. C. Bunting, M. D. Mayor, and O. R. Elía. 1997. Effect of fire on woody species in central semi-arid Argentina. Journal of Arid Environments 35:87-94.

Bran, D., G. Cecchi, and J. Ayese. 1991. Los dominios fisonómico-florísticos de la Prov. de Río Negro, XXIII Reunión Argentina de Botánica, Bariloche. 240.

Brown, A. D., H. R. Grau, L. Malizia, and A. Grau. 2001. Argentina. En: Kappelle M., and A. D. Brown (eds.). Bosques nublados del Neotrópico. Santo Domingo de Heredia, Costa Rica. INbio. 623:659.

Brown, A. D., and S. Pacheco. 2006. Propuesta de actualización del mapa ecorregional de la Argentina. Pp. 28-31 en A. D. Brown, U. M. Ortiz, M. Acerbi and J. Corcuera (eds.). La situación ambiental argentina 2005. Fundación Vida Silvestre, Buenos Aires.

Burkart, A. 1957. Ojeada sinóptica sobre la vegetación del Delta del Río Paraná. Darwiniana 11(3):457-561.

Burkart, R., N. Bárbaro, R. O. Sánchez, and D. A. Gómez. 1999. Ecorregiones de la Argentina, APN, PRODIA. Pp. 43.

Burkart, S. E., M. F. Garbulsky, C. M. Ghersa, J. P. Guerschman, R. J. C. León, M. Oesterheld, J. M. Paruelo, and S. B. Perelman. 2005. Las comunidades potenciales del pastizal pampeano bonaerense. Pp. 379-399 en M. Oesterheld, M. R. Aguiar, C. M. Ghersa and J. M. Paruelo (eds.). La heterogeneidad de la vegetación de los agroecosistemas. Un homenaje a Rolando León. Editorial Facultad de Agronomía, Buenos Aires.

Burkart, S. E., R. J. C. León, M. C. Conde, and S. B. Perelman. 2011. Plant species diversity in remnant grasslands on arable soils in the cropping Pampa. Plant Ecology 212:1009-1024

Burkart, S. E., R. J. C. León, and C. P. Movia. 1990. Inventario fitosociológico del pastizal de la Depresión del Salado (Prov. Bs. As.) en un área representativa de sus principales ambientes. Darwiniana 27-69.

Burkart, S. E., R. J. C. León, S. B. Perelman, and M. Agnusdei. 1998. The grasslands of the flooding pampa (Argentina): Floristic heterogeneity of natural communities of the southern Rio Salado basin. Coenoses 13:17-27.

Cabido, M., L. Carranza, A. Acosta, and S. Páez. 1991. Contribución al conocimiento fitosociológico del Bosque Chaqueño Serrano en la provincia de Córdoba, Argentina. Phytocoenologia 19:547-566.

Cabido, M., M. Giorgis, and M. Tourn. 2010. Guía para una excursión botánica en las Sierras de Córdoba. Boletín de la Sociedad Argentina de Botánica 45(1-2):209-219.

Cabido, M., C. González, A. Acosta, and S. Díaz. 1993. Vegetation changes along a precipitation gradient in Central Argentina. Vegetatio 109:5-14.

Cabido, M., A. Manzur, M. L. Carranza, and C. González Albarracín. 1994. La vegetación y el medio físico del Chaco Árido en la provincia de Córdoba, Argentina Central. Phytocoenologia 24:423-460.

Cabrera, A. L. 1947. La estepa patagónica. Pp. 249-273 en Geografía de la República Argentina. Tomo VIII. Sociedad Argentina de Estudios Geográficos, GAEA. Coni Editorial, Bs.As. Pp. 346.

Cabrera, A. L. 1976. Regiones fitogeográficas argentinas. Pp. 1-85 en W. F. Kugler (ed.). Enciclopedia Argentina de Agricultura y Jardinería. Tomo 2. 2da edición. Acme, Buenos Aires, Argentina. Fascículo 1.

Cabrera, A. L., and A. Willink. 1973. Biogeografía de América Latina. Monografía 13. Serie de Biología. Secretaría General de la Organización de los Estados Americanos. Washington DC. EEUU. Pp. 120.

Candia, R., S. Puig, A. Dalmasso, F. Videla, and E. Martínez Carretero. 1993. Diseño del plan de manejo para la reserva provincial La Payunia (Malargüe, Mendoza). Multequina 2:5-87.

Cano, E., B. Fernández, and M. A. Montes. 1980. Inventario integrado de los recursos naturales de la Provincia de La Pampa. Instituto Nacional de Tecnología Agropecuaria. Pp. 493.

Cardoso da Silva, J. M., and C. H. M. Casteleti. 2003. Status of the biodiversity of the Atlantic Forest of Brasil. Pp. 43-59 en C. Galindo-Leal and I. Gusmão Câmara (eds.). The Atlantic Forest of South America. Biodiversity Status, Threats, and Outlook. Island Press, Washington DC.

Carnevali, R. 1994. Fitogeografía de la Provincia de Corrientes. Gobierno de la Provincia de Corrientes. Instituto Nacional de Tecnología Agropecuaria. Pp. 324.

Casco, S., M. Neiff, and J. Neiff. 2005. Biodiversidad en Ríos del Litoral Fluvial. Utilidad del Software PULSO. Pp. 105-120 en F. G. Aceñolaza (ed.). Temas de la Biodiversidad del Litoral Fluvial Argentino II. INSUGEO, Miscelánea 14. Tucumán.

Cingolani, A. M., D. Bran, C. López, and J. Ayesa. 2000. Comunidades vegetales y ambiente en el ecotono boreal entre los distritos patagónicos Central y Occidental (Río Negro, Argentina). Ecología Austral 10:47-61.

Cingolani, A. M., D. Renison, M. R. Zak, and M. R. Cabido. 2004. Mapping vegetation in a heterogeneous mountain rangeland using landsat data: an alternative method to define and classify land-cover units. Remote Sensing of Environment 92:84-97.

Collantes, M. B., J. Anchorena, and A. M. Cingolani. 1999. The steppes of Tierra del Fuego: Floristic and growthform patterns controlled by soil fertility and moisture. Plant Ecology 140:61-75.

Damascos, M. A., D. Barthélémy, C. Ezcurra, P. Martínez, and C. Brion. 2008. Plant phenology, shoot growth, and branching pattern in Mulinum spinosum (Apiaceae), a cushion shrub of the arid Patagonian steppe of Argentina. Journal of Arid Environments 72:1977-1988.

Demaria, M. R., J. P. Martini, and D. F. Steinaker. 2016. Actualización del límite occidental del pastizal pampeano. Ecología Austral 26(1):59-63.

Dimitri, M. J. 1962. La flora andino-patagónica. Anales de Parques Nacionales, Tomo IX. Buenos Aires, Argentina. Pp. 130. 
Ferreyra, M., Cingolani, A., Ezcurra, C., and Bran, D. 1998. High-Andean vegetation and environmental gradients in northwestern Patagonia, Argentina. Journal of Vegetation Science 9:307-316.

Fontana, J. L. 1996. Los pajonales mesófilos semi-naturales de Misiones (Argentina). Phytocoenologia 26(2):179-271

Franceschi, E. A., D. E. Prado, and J. P. Lewis. 1985. Comunidades vegetales, y mapa de vegetación de la reserva El Rico e islas aledañas (Santa Fe). Universidad Nacional de Rosario, Rosario. Pp. 40.

Frangi, J. L. 1975. Sinopsis de las comunidades vegetales y el medio de las sierras de Tandil (Provincia de Buenos Aires). Boletín de la Sociedad Argentina de Botánica 16:293-319.

Frangi, J. L., and O. Bottino. 1995. Comunidades vegetales de la Sierra de la Ventana, Provincia de Buenos Aires, Argentina. Revista de la Facultad de Agronomía, La Plata 71:93-133.

Giraudo, A. R., H. Povedano, J. M. Belgrano, E. Krauczuck, U. Pardiñas, A. Miquelarena, D. Ligier, D. Baldo, and M. Castelino. 2003. Biodiversity Status of the Interior Atlantic Forest of Argentina. Pp 160-180 en C. Galindo-Leal and I. Gusmão Câmara (eds.). The Atlantic Forest of South America. Biodiversity status, Threats, and Outlook. Island Press, Washington DC.

Golluscio, R. A., F. P. Cavagnaro, and M. D. Valenta. 2011. Arbustos de la estepa patagónica: ¿adaptados a tolerar la sequía o el pastoreo? Ecología Austral 21:61-70.

Golluscio, R. A., R. J. C. León, and S. Perelman. 1982. Caracterización fitosociológica de la estepa del oeste de Chubut, su relación con el gradiente ambiental. Boletín de la Sociedad Argentina de Botánica 21:299-324.

Grau, H. R., and A. D. Brown. 1995. Patterns of tree species diversity along latitudinal and altitudinal gradients in the Argentinean subtropical montane forest. Pp. 295-300 en S. Churchill, E. Forero, J. Luteyn and E. Balslev (eds.). Biodiversity and Conservation of Neotropical Montane Forest. The New York Botanical Garden.

Hauman, L. 1916. La forêt valdivienne et ses limites: notes de géographie botanique. Peuser, Buenos Aires.

Hueck, K. 1972. Mapa de la vegetación de América del Sur (1:8.000.000). Forstliche Forschungsanstalt Munchen. Gustav Fisher Verlag, Stuttgart.

INTA. 1990. Atlas de suelos de la República Argentina. Versión digital (1:500000).

Karlin, M. S., U. O. Karlin, R. O. Coirini, G. J. Reati, and R. M. Zapata. 2013. El Chaco Árido. $1^{\circ}$ ed. Universidad Nacional de Córdoba. Córdoba. Pp. 420.

Kristensen, M. J., and J. L. Frangi. 1995. La Sierra de la Ventana: una Isla de Biodiversidad. Ciencia Hoy 5:25-34.

León, R. J. C., and D. L. Anderson. 1983. El límite occidental del pastizal pampeano. Mitteilungen der Floristischsoziologischen Arbeitsgeneinschaft. Tuexenia, Neue Serie 3:67-83.

León, R. J. C, D. Bran, M. Collantes, J. M. Paruelo, and A. Soriano. 1998. Grandes unidades de vegetación de la Patagonia extra andina. Ecología Austral 8:123-141.

León, R. J. C., S. E. Burkart, and C. P. Movia. 1979. La vegetación de la República Argentina. Relevamiento fitosociológico del pastizal del norte de la Depresión del Salado (Partido de Magdalena y Brandsen, prov. de Bs. As.). Instituto Nacional de Tecnología Agropecuaria. Serie Fitogeográfica 17:11-93.

León, R. J. C., and N. Marangón. 1980. Delimitación de comunidades en el pastizal puntano. Sus relaciones con el pastoreo. Bol. Soc. Argent. Bot. 19:277-288.

León, R. J. C., and C. P. Movia. 1981. Heterogeneidad de un establecimiento del espinal correntino-entrerriano. Modificaciones provocadas por el uso. Ecologia vegetal, Argentina. Gaceta Agronómica 1:276-292.

León, R. J. C., G. M. Rusch, and M. Oesterheld. 1984. Pastizales pampeanos - impacto agropecuario. Phytocoenologia 12:201-218.

Lewis, J. P. 1981. La vegetación de la provincia de Santa Fe. Pp. 121-148 en Estudios de geografía de la provincia de Santa Fe: Homenaje al Dr. Alfredo Castellanos. Sociedad Argentina de Estudios Geográficos.

Lewis, J. P., and M. B. Collantes. 1973. El Espinal Periestépico. Ciencia e Investigación 29:360-377.

Lewis, J. P., M. B. Collantes, E. F. Pire, N. J. Carnevale, S. I. Boccanelli, S. L. Stofella, and D. E. Prado. 1985. Floristic groups and plant communities of southeastern Santa Fe, Argentina. Vegetatio 60(2):67-90.

Lewis, J. P., S. Noetinger, D. E. Prado, and I. M. Barberis. 2009. Woody vegetation structure and composition of the last relicts of Espinal vegetation in subtropical Argentina. Biodiversity and Conservation 18(13):3615-3628.

Lewis, J. P., E. F. Pire, D. E. Prado, S. L. Stofella, E. Franceschi, and N. Carnevale. 1990. Plant communities and phytogeographical position of a large depression in the Great Chaco, Argentina. Vegetatio 86(1):25-38.

Lizzi, J. M, M. F. Garbulsky, R. A. Golluscio, and A. V. Deregibus. 2007. Mapeo indirecto de la vegetación de Sierra de la Ventana, provincia de Buenos Aires. Ecología Austral 17:217-230.

López, R. P. 2000. La prepuna boliviana. Ecología en Bolivia 34:45-70.

López, R. P., and S. Beck. 2002. Phytogeographical affinities and life form composition of the Bolivian Prepuna. Candollea 57:77-96.

Luti, R., M. Solís, F. Galera, N. Müller de Ferreira, and M. Berzal. 1979. Vegetación. Pp 297-368. En: Vázquez, J., R. Miatello, and M. Roque (eds.). Geografía Física de la Provincia de Córdoba. Ed. Boldt. Buenos Aires, Argentina.

Malvárez, J. 1997. Las comunidades vegetales del Delta del Río Paraná. Su relación con factores ambientales y patrones de paisaje. Tesis doctoral, UBA, Buenos Aires.

Martínez, G., M. D. Arana, A. J. Oggero, and E. S. Natale. 2016. Biogeographical relationships and new regionalisation of high-altitude grasslands and woodlands of the central Pampean Ranges (Argentina), based on vascular plants and vertebrates. Australian Systematic Botany 29:473-488. 
Martínez Carretero, E. 1995. La Puna Argentina: delimitación general y división en distritos florísticos. Boletín de la Sociedad Argentina de Botánica 31(1-2):27-40.

Martínez Carretero, E. 2004. La provincia fitoogeográfica de la Payunia. Boletín de la Sociedad Argentina de Botánica 39:195-226.

Martínez Carretero, E., A. M. Faggi, J. L. Fontana, P. Aceñolaza, R. Gandullo, M. Cabido, D. Iriart, D. Prado, F. A. Roig, and U. Eskuche. 2016. Prodromus Sinsistemático de la República Argentina y una breve introducción a los estudios fitosociológicos. Bol Soc Argent Bot 51:469-549.

Martínez-Crovetto, R. 1963. Esquema fitogeográfico de la Provincia de Misiones (República Argentina). Bonplandia 1:171-223.

Martínez-Crovetto, R. 1965. Estudios Ecologicos En Los Campos Del Sur De Misiones: I. Efecto del pastoreo sobre la estructura de la vegetación. Bonplandia 2(2):29-73.

Martínez-Crovetto, R., and B. G. Piccinini. 1950. La vegetación de la República Argentina I. Los Palmares de Butia yatay. Revista de Investigaciones Agrícolas 4(2):153-241.

Matteuci, S. D., J. Morello, A. F. Rodríguez, and N. E. Mendoza. 2004. El Alto Paraná encajonado argentino-paraguayo. Mosaicos de paisaje y conservación regional. Ediciones FADU, UNESCO. Pp. 160.

Menghi, M. 2006. Vegetación. Pp. 173-189 enE. H. Bucher (ed.). Bañados del Río Dulce y Laguna Mar Chiquita. Academia Nacional de Ciencias. Córdoba.

Morales, J. M., M. Sirombra, and A. D. Brown. 1995. Riqueza de Arboles en las Yungas argentinas. Pp. 163-174 en A. D. Brown, and H. R. Grau (eds.). Investigacion, conservación y desarrollo en selvas subtropicales de montaña. Laboratorio de Investigaciones Ecologicas de las Yungas, Universidad Nacional de Tucuman. Tucuman. Argentina.

Morello, J. 1958. La provincia fitogeográfica del Monte. Opera Lilloana II. Pp. 155.

Morello, J., and J. Adámoli. 1967. Vegetación y Ambiente del Nordeste del Chaco Argentino (Guía de Viaje, tramo Resistencia-Puerto Pilcomayo). IX Jornadas Botánicas Argentinas. Boletín EEA Colonia Benítez 3:1-75

Morello, J., and J. Adámoli. 1968. Las grandes unidades de vegetación y ambiente del Chaco Argentino. Primera parte: Objetivos y metodología. Instituto Nacional de Tecnología Agropecuaria. Serie Fitogeográfica 10:1-125.

Morello, J., and J. Adámoli. 1974. Las grandes unidades de vegetación y ambiente del Chaco Argentino. Segunda parte: Vegetación y Ambiente de la provincia del Chaco. Instituto Nacional de Tecnología Agropecuaria. Serie Fitogeográfica 13:1-130.

Morello, J., N. E. Crudelli, and M. Saraceno. 1971. Los vinalares de Formosa (República Argentina). La colonizadora leñosa Prosopis ruscifolia Gris. Instituto Nacional de Tecnología Agropecuaria. Serie Fitogeográfica 11:1-111.

Morello, J., S. Matteucci, A. Rodríguez, and M. Silva. 2012. Ecorregiones y complejos ecosistémicos argentinos. Ed: Orientación Gráfica Editora. Pp. 752.

Morrone, J. J. 2014. Biogeographical regionalisation of the Neotropical region. Zootaxa 3782:1-110.

Neiff, J. 1997. El régimen de pulsos en ríos y grandes humedales de Sudamérica. Pp. 1-49 en A. I. Malvárez, and P. Kandus (eds.). Tópicos sobre grandes humedales sudamericanos. ORCYT-MAB (UNESCO), Montevideo, Uruguay.

Oakley, L. J., D. E. Prado, and J. Adámoli. 2005. Aspectos biogeográficos del corredor fluvial Paraguay-Paraná. Miscelánea INSUGEO 14:245-258.

Parodi, L. R. 1930. Ensayo fitogeográfico sobre el Partido de Pergamino. Revista de la Facultad de Agronomía y Veterinaria 1:65-270

Parodi, L. R. 1940. La distribución geográfica de los talares en la provincia de Buenos Aires. Darwiniana 4:33-56.

Paruelo, J. M., A. Beltrán, E. G. Jobbagy, O. E. Sala, and R. A. Golluscio. 1998. The climate of Patagonia: general patterns and controls on biotic processes. Ecología Austral 8:85-101.

Paruelo, J. M., and W. Lauenroth. 1996. Relative abundance of plant functional types in grasslands and shrublands of North America. Ecological Applications 6:1212-1224.

Pennington, R. T., M. Lavin, and Oliveira-Filho A. 2009. Woody plant diversity, evolution and ecology in the tropics: perspectives from seasonally dry tropical forests. Annual Review of Ecology, Evolution and Systematics 40:437457.

Perelman, S. B., S. E. Burkart, and R. J. C. Leon. 2003. The role of a native tussock grass (Paspalum quadrifarium Lam.) in structuring plant communities in the Flooding Pampa grasslands, Argentina. Biodiversity and Conservation 12(2): 225-238.

Perelman, S. B., R. J. C. León, and M. Oesterheld. 2001. Cross-scale vegetation patterns of Flooding Pampa grasslands. Journal of Ecology 89:562-577.

Pizzio, R. M., and O. Royo-Pallarés. 1994. Utilización y manejo de los pastizales del ecosistema Campos de Argentina. IICA-BID-PROCISUR. Diálogo XL- Utilización y manejo de pastizales. Pp. 115-126.

Prado, D. E. 1993a. What is the Gran Chaco vegetation in South America? I. A review. Contribution to the study of flora and vegetation of the Chaco. V. Candollea 48:145-172.

Prado, D. E. 1993b. What is the Gran Chaco vegetation in South America? II. A redefinition. Contribution to the study of flora and vegetation of the Chaco. VII. Candollea 48:615-629.

Prado, D. E. 1995. Selva pedemontana: contexto regional y lista florística de un ecosistema en peligro. Pp. 19-52 en A. D. Brown and H. R. Grau (eds.). Investigación, Conservación y Desarrollo en Selvas Subtropicales de Montaña. Laboratorio de Investigaciones Ecologicas de las Yungas, Universidad Nacional de Tucuman. Argentina.

Prado, D. E. 2000. Seasonally dry forests of tropical South America: from forgotten ecosystems to a new phytogeographic unit. Edinburgh Journal of Botany 57:437-461.

Prado, D. E., E. A. Franceschi, and M. B. Bianchi. 1989. El bosque del escarpe occidental del Río Paraná (Argentina). Composición florística y estructura. Acta Botânica Brasilica 3:99-108. 
Ragonese, A. E. 1951. Estudio fitosociológico de las Salinas Grandes. Revista de Investigaciones Agrícolas 5(1-2): $1-234$.

Ragonese, A. E., and J. Castiglioni. 1970. La vegetación del Parque Chaqueño. Boletín de la Sociedad Argentina de Botánica 11(Supl.):133-160.

Ragonese, A. E., and G. Covas. 1947. La Flora Halófila del Sur de la Provincia de Santa Fe (República Argentina). Darwiniana 7(3):401-496.

Renison, D., G. A. E. Cuyckens, S. Pacheco, G. F. Guzmán, R. Grau, P. Marcora, G. Robledo, A. M. Cingolani, J. Dominguez, M. Landi, L. Bellis, and I. Hensen. 2013. Distribución y estado de conservación de las poblaciones de árboles y arbustos del género Polylepis (Rosaceae) en las montañas de Argentina. Ecología Austral 23:27-36.

Ribichich, A. M. 2002. El modelo clásico de la fitogeografía de Argentina: Un análisis crítico. Interciencia 27:669-675.

Ríos, R. C., F. Galvão, and G. Ribas Curcio. 2010. Estructura de las principales especies arbóreas en el Parque Cruce Caballero y su similitud florística con áreas de Argentina y Brasil. Ciência Florestal 20:193-206

Roig, F. A. 1972. Bosquejo fisonómico de la vegetación de la provincia de Mendoza. Boletín de la Sociedad Argentina de Botánica 13:49-80.

Roig, F. A., J. Anchorena, O. Dollenz, A. M. Faggi, and E. Méndez. 1985. Las comunidades vegetales de la Transecta Botánica de la Patagonia Austral. Primera parte: la vegetación del área continental. Pp 350-456 en O. Boelcke, D. M Moore and F. A. Roig (eds.). Transecta Botánica de la Patagonia Austral. CONICET (Argentina), Royal Society (UK) e Instituto de la Patagonia (Chile).

Roig, F. A., E. Martínez Carretero, and E. Méndez. 1996. Mapa de Vegetación de la Provincia de Mendoza. Instituto Argentino de Investigaciones de las Zonas Áridas - CRICYT, Mendoza, Argentina.

Roig, F. A., S. Roig-Juñent, and V. Corbalán. 2009. Biogeography of the Monte Desert. Journal of Arid Environments 73:164-172.

Ruiz Leal, A. 1972. Flora popular mendocina. Deserta 3:9-296.

Ruthsatz, B., and C. P. Movia. 1975. Relevamiento de las estepas andinas del noreste de la provincia de Jujuy, República Argentina. Fundación para la Educación la Ciencia y la Cultura. Pp. 127.

Sayago, M. 1969. Estudio Fitogeográfico del Norte de Córdoba. Boletín de la Academia Nacional de Ciencias 46(2,3 y 4$): 123-427$.

van der Sluijs, D. H. 1971. Native grasslands of the Mesopotamia region of Argentina. Netherlands Journal of Agricultural Science 19:3-22.

Soriano, A. 1956. Los distritos florísticos de la provincia Patagónica. Revista de Investigaciones Agropecuarias 10: 323-347.

Soriano, A., R. J. C. León, O. E. Sala, R. S. Lavado, V. A. Deregibus, M. A. Cahuepé, O. A. Scaglia, C. A. Velázquez, and J. H. Lemcoff. 1991. Río de la Plata grasslands. Pp 367-407 en R. T. Coupland (ed.). Ecosystems of the world 8A. Natural grasslands. Introduction and western hemisphere. Elsevier, New York.

Speck, N. H. 1982. Vegetación y pasturas de la zona Ingeniero Jacobacci-Maquinchao. Pp. 157-208 en INTA (ed.). Sistema Fisiográfico de la Zona Ingeniero Jacobacci-Maquinchao (Prov. Rio Negro). INTA, Buenos Aires.

Torrella, S., L. Oakley, R. Ginzburg, J. Adámoli, and L. Galetto. 2011. Estructura, composición y estado de conservación de la comunidad de plantas leñosas del bosque de tres quebrachos en el Chaco Subhúmedo Central. Ecología Austral 21:179-188.

Vervoorst, F. B. 1967. Las comunidades vegetales de la depresión del Salado (Provincia de Buenos Aires). Instituto Nacional de Tecnología Agropecuaria. Serie Fitogeográfica 7:1-262.

Wingenroth, M., and J. Suárez. 1984. Flores de Los Andes. Alta montaña de Mendoza. IANIGLA (ed.). CRICYT, Mendoza. Pp. 144

\section{MATERIAl Suplementario}

Apéndice 1: Fuentes bibliográficas utilizadas para delimitar cada unidad de vegetación, y coincidencia cartográfica entre la unidad de vegetación y trabajos anteriores (ver también Figura 1).

Appendix 1: Bibliography references used to delimit each unit of vegetation, and cartographic coincidence between the vegetation unit and previous works (see also Figure 1).

http://ojs.ecologiaaustral.com.ar/index.php/Ecologia_Austral/article/view/399/295

Apéndice 2: Archivos electrónicos con vistas de alta definición del mapa de unidades de vegetación de la Argentina (Figura 1).

Appendix 2: Digital files with high-definition views of the map of vegetation units of Argentina (Figure 1).

http://ojs.ecologiaaustral.com.ar/index.php/Ecologia_Austral/article/view/399/293

Apéndice 3:Archivos electrónicos vectoriales del mapa de unidades de vegetación de la Argentina (Figura 1), de los principales ríos, de las ciudades capitales, y de los límites políticos nacionales y provinciales.

Appendix 3:Vector files for the map of vegetation units of Argentina (Figure 1), main rivers, capital cities and national and provinces political boundaries.

http:/ / ojs.ecologiaaustral.com.ar/index.php/Ecologia_Austral/article/view/399/294

Apéndice 4: Lista de nombres botánicos completos de los géneros y especies citadas.

Appendix 4: Scientific names of cited genera and species.

http:/ /ojs.ecologiaaustral.com.ar/index.php/Ecologia_Austral/article/view/399/296 